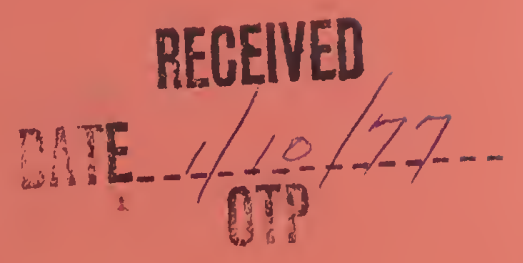

\title{
A MICROWAVE VECTOR VOLTMETER SYSTEM
}

Keith C. Roe

Cletus A. Hoer

Electromagnetic Division

Institute for Basic Standards

National Bureau of Standards

Boulder, Colorado 80302

August 1976

Sponsored by

Department of the Air Force

USAF School of Aerospace Medicine

Brooks Air Force Base, Texas 78235 



\section{NBSIR $76-844$}

\section{A MICROWAVE VECTOR VOLTMETER SYSTEM}

Keith C. Roe

Cletus A. Hoer

Electromagnetic Division

Institute for Basic Standards

National Bureau of Standards

Boulder, Colorado 80302

August 1976

Sponsored by

Department of the Air Force

USAF School of Aerospace Medicine

Brooks Air Force Base, Texas 78235

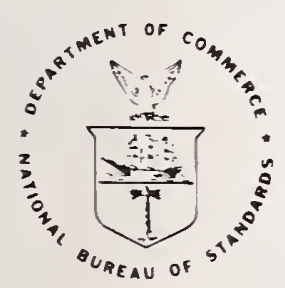

U.S. DEPARTMENT OF COMMERCE, Elliot L. Richardson, Secretary

Edward O. Vetter, Under Secretary

Dr. Betsy Ancker-Johnson, Assistant Secretary for Science and Technology

NATIONAL BUREAU OF STANDARDS, Ernest Ambler, Acting Director 
$\underline{\text { Page }}$

ABSTRACT . . . . . . . . . . . . . . . . . . . . . . . . 1

I. INTRODUCTION . . . . . . . . . . . . . . . . . 1

II. DESCRIPTION . . . . . . . . . . . . . . . . . . . . . 1

General . . . . . . . . . . . . . . . . 1

Seven-Port Junction . . . . . . . . . . . . . . . 2

System Operation . . . . . . . . . . . . . . 4

III. SEVEN-PORT CALIBRATION . . . . . . . . . . . . . . . . 7

General . . . . . . . . . . . . . . . . . 7

Broadband two-position insertion device . . . . . . . . 7

Broadband three-position phase shifter . . . . . . . . 10

IV. MEASUREMENT . . . . . . . . . . . . . . . . . . 12

Applications . . . . . . . . . . . . . . . 12

Tasks . . . . . . . . . . . . . . . . 13

V. OPERATING PROCEDURE . . . . . . . . . . . . . . 14

Turn-on . . . . . . . . . . . . . . . . . 14

Program . . . . . . . . . . . . . . . . 15

Operating . . . . . . . . . . . . . . . 15

VI. ERRORS . . . . . . . . . . . . . . . . . . . 16

Detector nonlinearity . . . . . . . . . . . . 16

Step attenuator nonrepeatability . . . . . . . . . . 16

Frequency drift . . . . . . . . . . . . . . . 17

Leakage signals . . . . . . . . . . . . . . . . 17

Signal level variation . . . . . . . . . . . . . 18

VII. EVALUATION . . . . . . . . . . . . . . . . . . . . . 18

System repeatability . . . . . . . . . . . . . . 18

Intercomparison . . . . . . . . . . . . . . . 18

VIII. TROUBLESHOOTING . . . . . . . . . . . . . . 20

IX. BIBLIOGRAPHY . . . . . . . . . . . . . . . . . . . . . . . . . . . 21

APPENDIX A - USING AN ARBITRARY SIX-PORT JUNCTION TO MEASURE

COMPLEX VOLTAGE RATIOS . . . . . . . . . . 23

APPENDIX B - CONTROL COMMANDS USED IN THE COMPUTER

OPERATING PROGRAM . . . . . . . . . . . . 33

APPENDIX C - COMPUTER PROGRAM DESCRIPTION AND LISTING
WITH SAMLE PRINTOUT . . . . . . . . . . 37

APPENDIX D - INTERFACE CABLE PIN CONNECTIONS . • . . • . . . . . 53

APPENDIX E - DIAGNOSTIC PROGRAM LISTING WITH SAMPLE PRINTOUTS . • 61 


\section{LIST OF FIGURES}

Figure

$\underline{\text { Page }}$

1. The microwave vector voltmeter system . . . . . . . . . . . 2

2. A front view of the microwave vector voltmeter . . . . . . . . 2

3. The seven-port junction and isolators used in the MVV . . . . . . 3

4. The seven-port junction and its diode detectors . . . . . . . . 4

5. Circuit used for self-calibration, measurement and diode linearity in the MVV system . . . . . . . . . . . . . . 5

6. A view of the chassis containing the seven-port junction and self-calibration circuitry . . . . . . . . 6

7. Using a quadrature hybrid (Q) and a power divider (D) to make an insertion ratio of $3 \mathrm{~dB}$ with $45^{\circ}$ phase shift . . . 8

8. A two-position repeatable insertion device . . . . . . . . . 8

9. Insertion loss and phase shift of the broadband two-position insertion device . . . . . . . . . . . . . . 9

10. A broadband three position phase shifter . . . . . . . . . . 10

11. Photograph of a broadband three-position phase shifter . • . . 10

12. Phase shift through the quadrature hybrid shown in figure 1 relative to the bottom coax line, measured on the NBS automatic network analyzer . . . . . . . . . . . . . 11

13. Some measurement configurations using the microwave vector voltmeter. Device D may be either a power divider or a directional coupler . . . . . . . . . . . . . . 12

\section{LIST OF TABLES}

Table

$\underline{\text { Page }}$

I. Attenuation Measurement Difference (dB) . . . . . . . . . . 19

II. Phase Shift Measurement Difference (degrees) . . . . . . . 19 


\section{A MICROWAVE VECTOR VOLTMETER SYSTEM}

Keith C. Roe and Cletus A. Hoer

This report presents a system description and operating procedure for a vector voltmeter system which covers the frequency range .5 to $12 \mathrm{GHz}$. The design is based upon a seven-port junction where phase and amplitude information is obtained using only power detectors. The system is computer controlled and self-calibrating for ratio measurements.

KEY WORDS: Amplitude; computer controlled; diode detectors; microwave measurements; phase anqle; selfcalibration; seven-port junction; vector voltmeter.

\section{INTRODUCTION}

The theory for using six, seven, and eight-port junctions to measure circuit parameters has developed rapidly at the National Bureau of standards in the past three years [1 - 7]. One of the applications of that theory is a microwave vector voltmeter (MVV) used to make measurements of complex substitution loss, or gain, ratios.

This report describes a complete MVV system which includes a sevenport junction, computer, digital voltmeter, multiplexing unit, switching circuits, and self-calibration devices.

\section{DESCRIPTION}

General

The MVV system has two input ports or channels (labeled "reference" and "test") for comparison of voltage level changes in the test channel while the reference channel level is maintained constant. The complex ratio of the voltage change in the test channel may be measured at any frequency in the 0.5 to $12 \mathrm{GHz}$ range with power levels not exceeding $+10 \mathrm{dBm}$ at either of the two input ports. The lower limit of power at the reference port is $-20 \mathrm{dBm}$ and at the test port is $-70 \mathrm{dBM}$.

The basic design of the MVV is based upon the six-port concept [I - 7] where phase and amplitude information can be obtained from a set of amplitude measurements. (In the MVV, diode detectors whose output voltages are very nearly a linear function of the square of their respective input voltages are used to indicate amplitude levels.) The seven-port approach may be regarded as an augmented version of the six-port technique. This was motivated by preliminary experiments, which indicated an improvement in measurement precision with one additional power detector.

A block diagram in figure 1 shows the interrelationship between the major parts of the complete system. All interconnecting lines in figure 1 represent interface cables for switching control or data transfer. 
The computer is used for data storage and calculation as well as automatic control of the system to minimize operator involvement and reduce the time required for the calibration and measurement processes. The switch driver, multiplexer and DVM are necessary for automatic control and data handling.

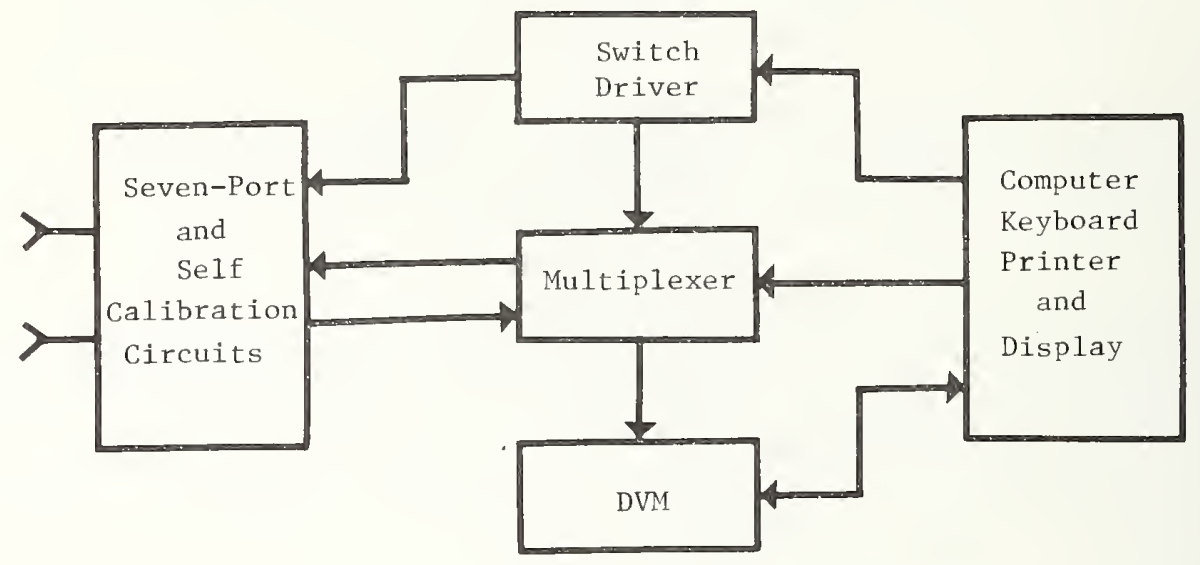

Figure 1. The microwave vector voltmeter system.

More detail is given in the following sections concerning the operation and functions of the MVV components shown in figure 1. Figure 2 shows the assembled system where the multiplexer, DVM, switch driver, seven-port and self-calibration circuits are contained within the cabinet on the right and the computer and keyboard are in the cabinet at the left.

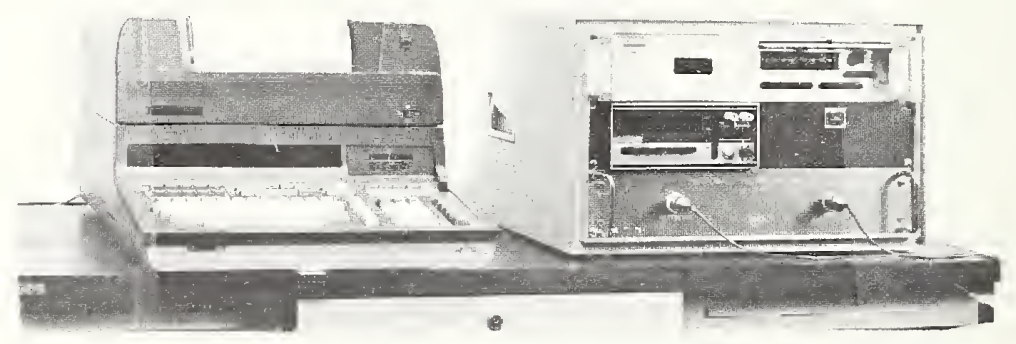

Figure 2. A front view of the microwave vector voltmeter.

\section{Seven-Port Junction}

The seven-port junction is constructed using quadrature hybrid $3 \mathrm{~dB}$ couplers $(Q)$ and $3 \mathrm{~dB}$ power dividers as shown in figures 3 and 4 . 
For incident waves $\mathrm{a}_{1}$ and $\mathrm{a}_{2}$ at ports 1 and 2 the ideal response at each of the power detectors $\mathrm{P}_{3}, \mathrm{P}_{5}, \mathrm{P}_{6}, \mathrm{P}_{7}$ and $\mathrm{P}_{8}$ would be proportional to the quantities indicated in figure 3. The ratio of the two incident waves would be

$$
\frac{a_{2}}{a_{1}} \propto \frac{\left(P_{5}-P_{7}\right)+j\left(P_{6}-P_{8}\right)}{P_{3}} .
$$

Since non-ideal components are used resulting in reflections, losses and uneven power division, the seven-port junction must be analyzed in a more general way. This is done in Appendix A for a six-port junction. A minor extension of that analysis can be performed for a seven-port junction resulting in equations (1) through (10), (Appendix A) where the summations are taken over 5 detectors instead of 4. The result is (from (10), Appendix A)

$$
\frac{a_{2}}{a_{1}}=K-\frac{\sum z_{i} P_{i}}{\sum{ }^{w_{i}} P_{i}}, \quad i=3,5,6,7,8^{*}
$$

The terms $\mathrm{K}, \mathrm{z}_{i}$, and $\mathrm{w}_{i}$, are constants of proportionality that can be determined in calibration. For measurements of the ratio of two different values of $a_{2}$ ( $a_{1}$ remains constant) the complex constant, $K$, does not need to be known. Since one of the $z_{i}=1$ and one of the $w_{i}=1$, this leaves four complex $z_{i}$ and four real $\mathrm{w}_{i}$, to be determined by the calibration. The self calibration process is described in section III of this report.

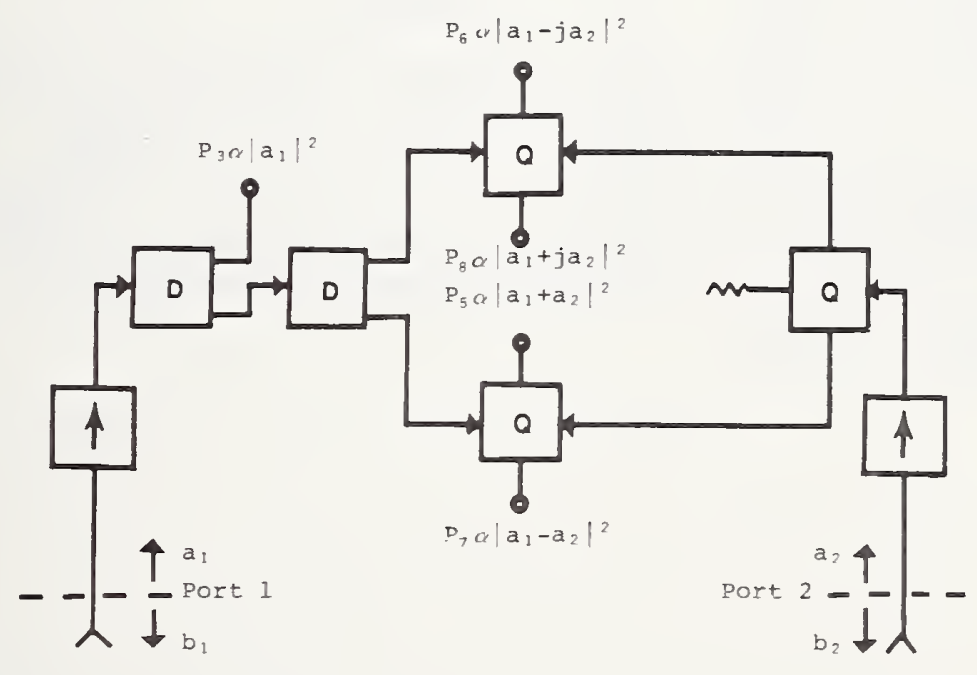

Figure 3. The seven-port junction and isolators used in the MVV.

* The subscripts are so labeled to be consistent with previous publications. 


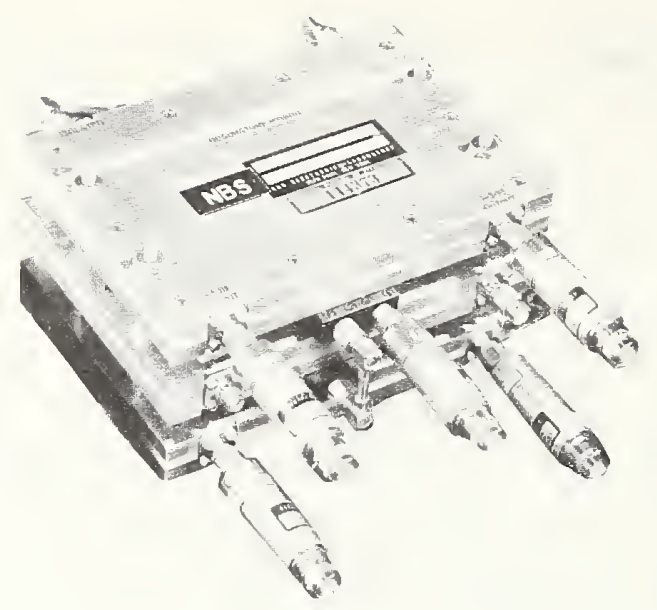

Figure 4. The seven-port junction and diode detectors.

\section{System Operation}

To make measurements the seven-port junction must first be calibrated, and then switched into a measurement routine. Three routines are available through software (Appendix C) supplied with the system. These routines are:

1. Self Calibration

2. Measurement

3. Diagnostic.

These routines contain control commands (Appendix B) which set the switches shown in figures 5 and 6 . The four outer switches $(1,3,6,7)$ are set to " $M$ " to measure or position "C" to calibrate the seven-port junction. The three inner switches (2, 4, and 5) are set to "S" for calibration and measurement or to "D" for diagnostics and diode linearity. 


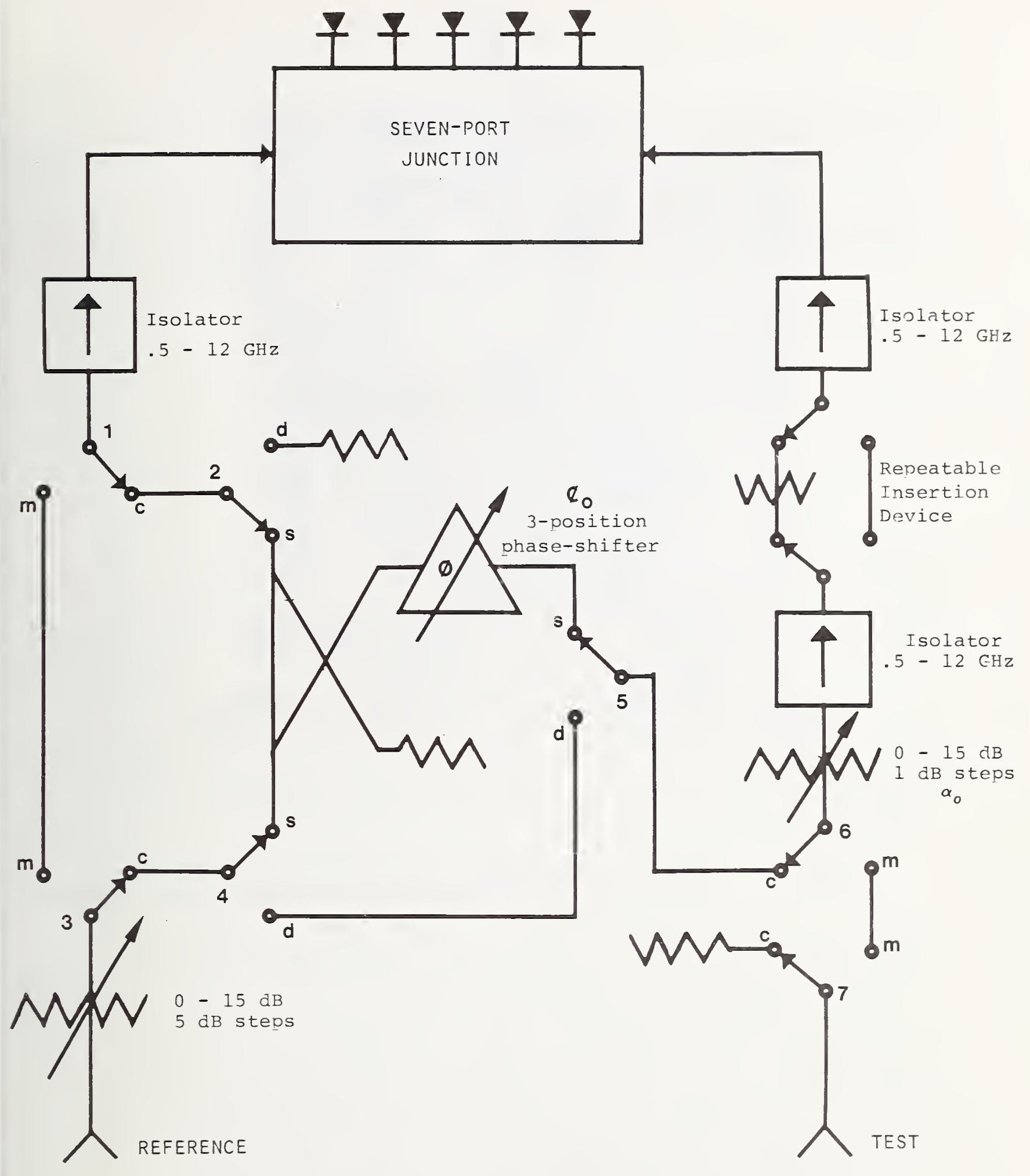

Figure 5. Circuit used for self-calibration, measurement and diode linearity in the MVV system. 


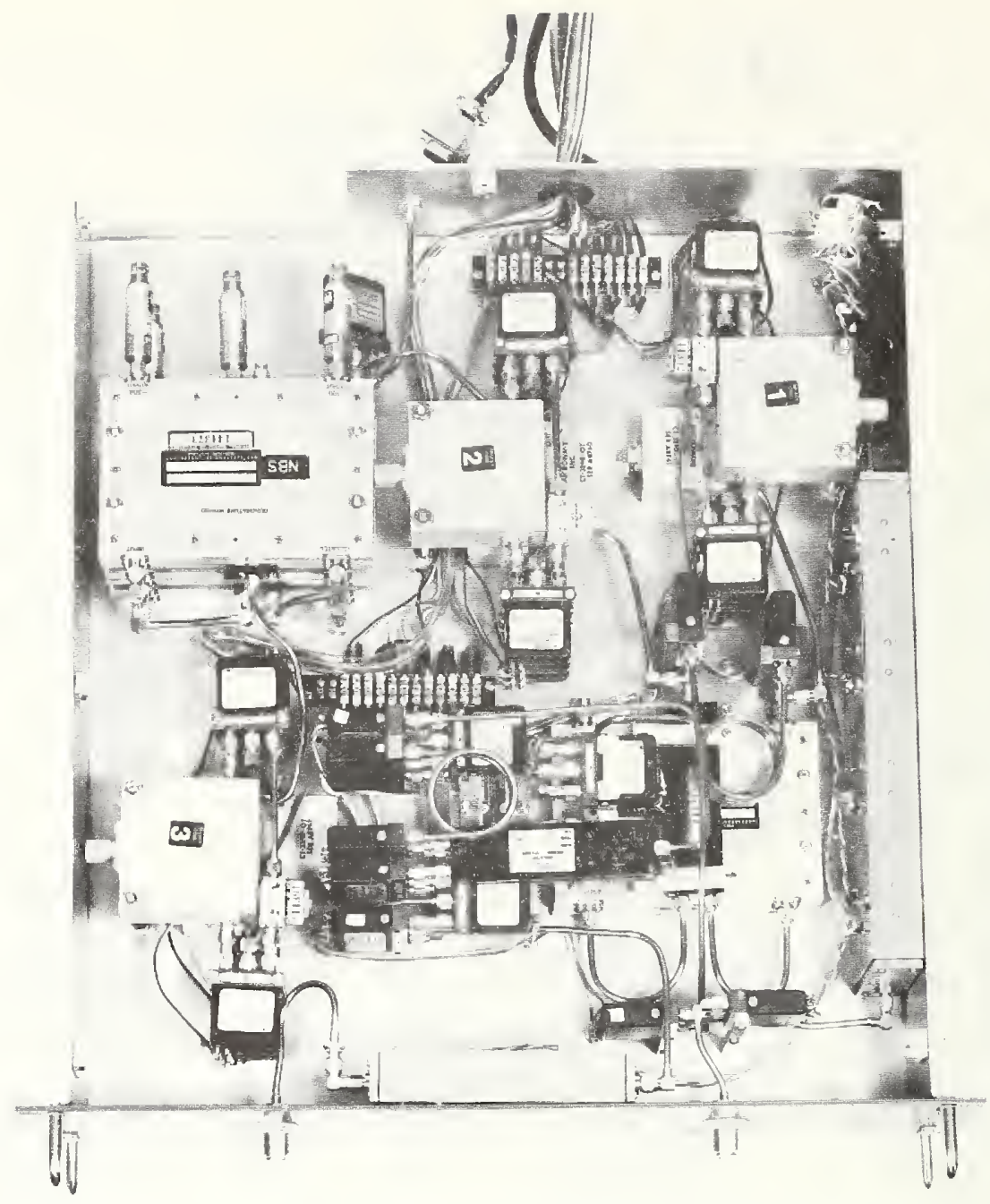

Figure 6. A view of the chassis containing the seven-port junction and self calibration circuitry. 
General

The self-calibration procedure is almost identical to the procedure outlined in [7] and reproduced in Appendix A. The only change is that $i$ goes from 3 to 7 instead of 3 to 6 .

Six independent measurements of the repeatable insertion device are obtained corresponding to these six nominal settings of $\phi_{0}$ (three-position phase shifter) and $\alpha_{0}(0-15 d B, 1 d B$ step).

$\begin{array}{cc}\alpha_{0}(\mathrm{~dB}) & \frac{\phi_{0} \text { (degrees) }}{0} \\ & 0^{\circ} \\ 0 & 120^{\circ} \\ 3 & 240^{\circ} \\ 3 & 240^{\circ} \\ 3 & 120^{\circ} \\ 0 & 0^{\circ}\end{array}$

These values of attenuation and phase shift for $\alpha_{0}$ and $\phi_{0}$ were chosen to obtain six symmetrically spaced points in the complex plane. The values are only approximate and need not be known for the self-calibration process. The only requirement is that no two points coincide for any frequency in the range 0.5 to $12 \mathrm{GHz}$.

The attenuation change, $a_{0}$, is easily obtained using commercially available equipment, however, the phase shifter $\left(\phi_{0}\right)$ and the repeatable insertion device $(L)$ are specially constructed to obtain broadband operation. More detail is provided about those circuits and their operation in the following sections.

\section{Broadband two-position insertion device}

In calibrating the seven-port junction, the complex insertion ratio $\mathrm{L}$ of the repeatable two-position insertion device must not have a phase angle of $0^{\circ}$ or multiples of $90^{\circ}$. A phase shift of $45^{\circ}$ is probably optimum, but doesn't need to be exact or known. One way of getting $45^{\circ}$ phase shift over a broad frequency range is shown in figure 7. The two outputs of the quadrature hybrid (Q) are equal in amplitude but $90^{\circ}$ out of phase. Adding these two signals with an in-phase power divider. (D) gives a signal that is shifted $45^{\circ}$ relative to the input signal. In addition to this $45^{\circ}$ there will be some phase shift $\theta$ due to the lengths of line through $Q$ and $D$. The length of the lower path can be adjusted to give a phase shift equal to $\theta$. The phase difference in the two switch positions will be $45^{\circ}$ over the complete frequency range of the hybrid and divider, which is the same as the frequency range of the 
seven-port. The amplitude of the insertion ratio will be approximately $3 \mathrm{~dB}$. The assembled two-position insertion device is shown in figure 8 . Measurements of the phase and insertion ratio are shown in the graph of figure 9 .

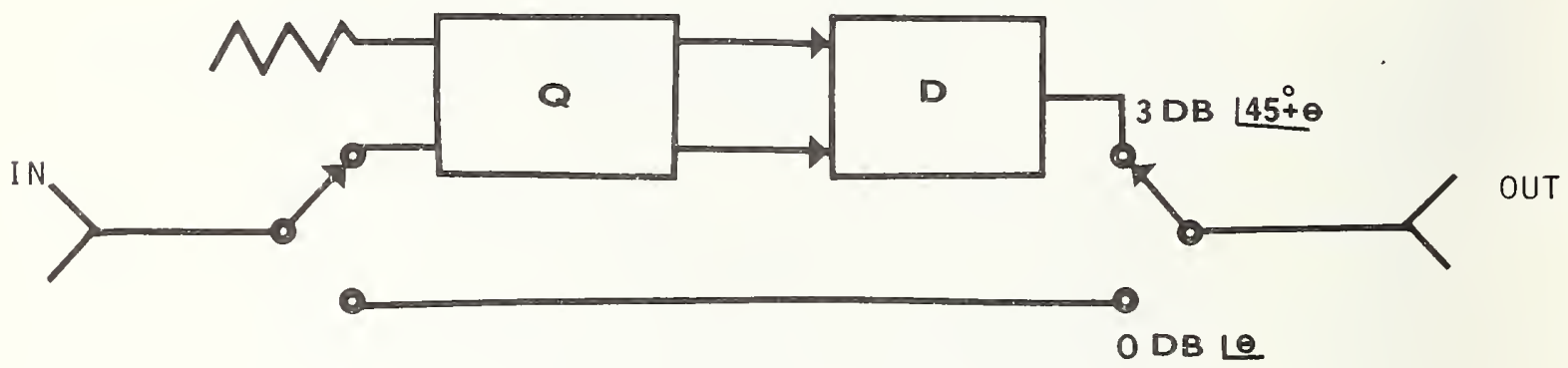

Figure 7. Using a quadrature hybrid (O) and at power divider (D) to make an insertion ratio of $3 \mathrm{~dB}$ with $45^{\circ}$ phase shift.

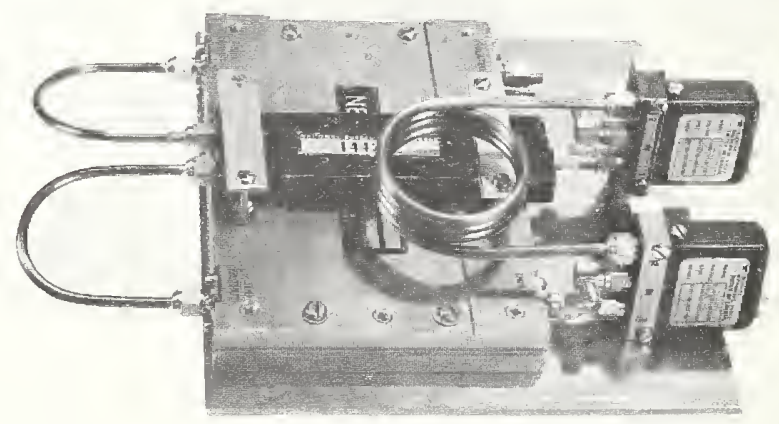

Figure 8. A two-position repeatable insertion device. 


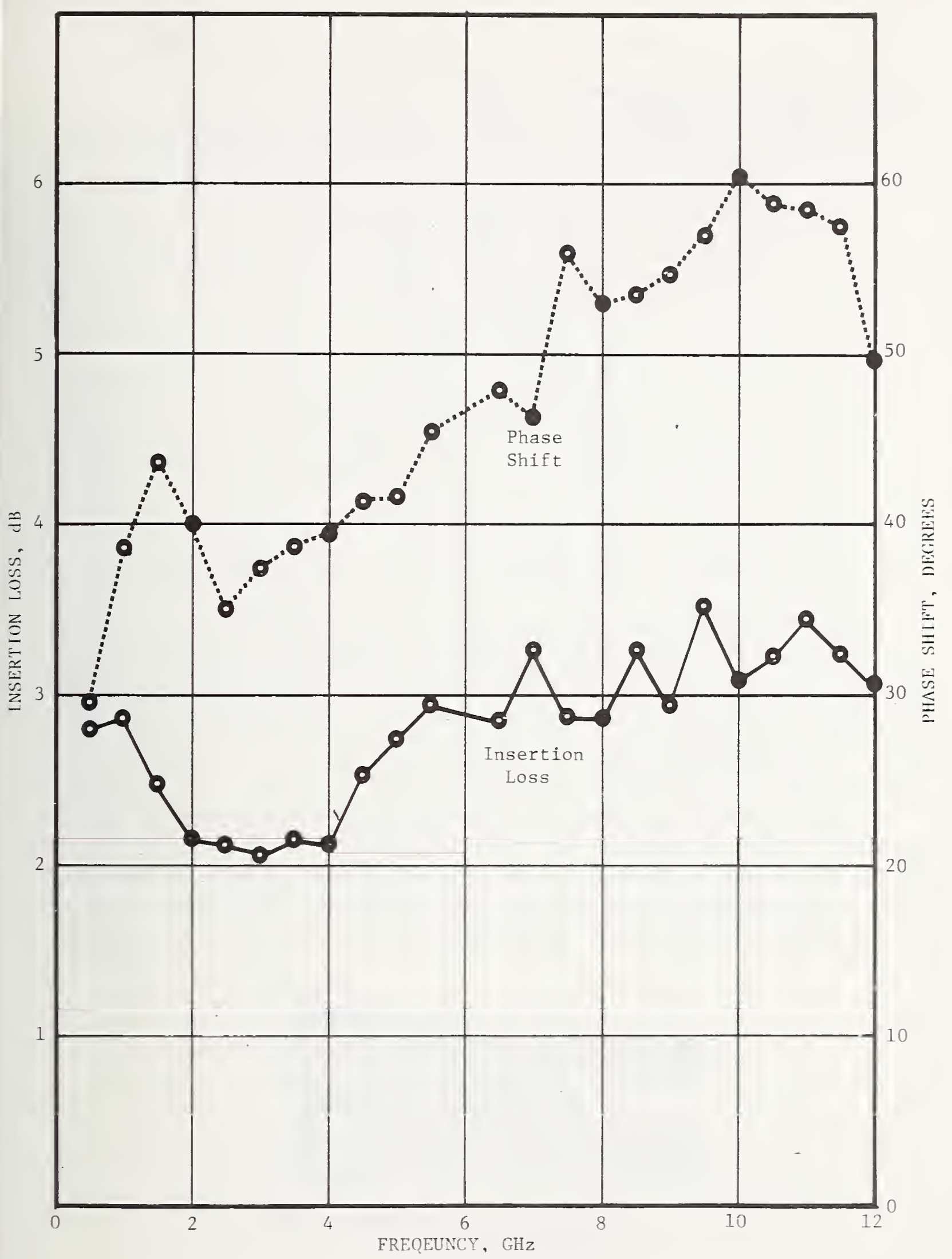

Figure 9. Insertion loss and phase shift of the broadband two-position insertion device. 
The phase shifter shown in figure 10 gives three different values of phase over the usable frequency range of the quadrature hybrid $(Q)$.

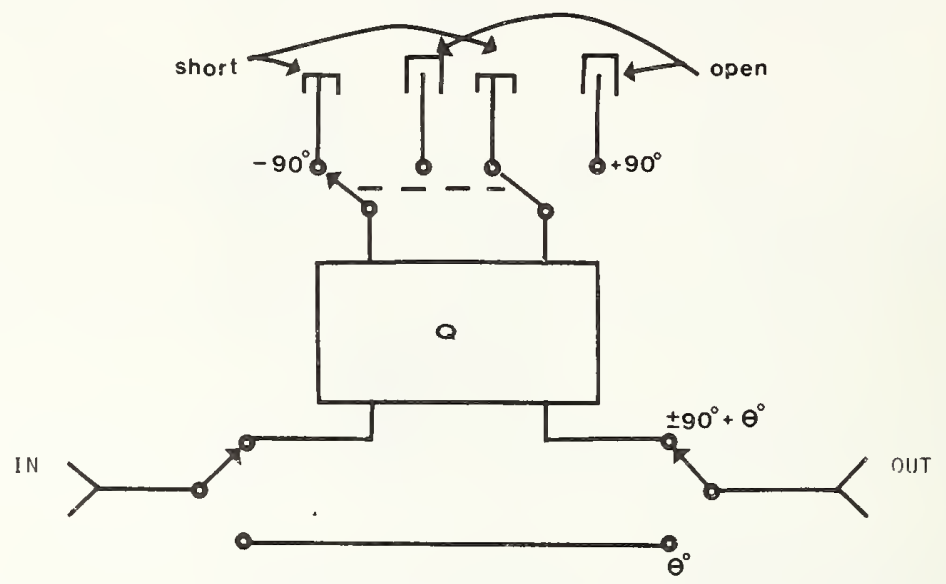

Figure 10. A broadband three-position phase shifter.

Going through the hybrid ( $Q$ ) the phase shift is theoretically either $\theta-90^{\circ}$ or $\theta+90^{\circ}$ depending on whether the outputs are shorted or open. The phase shift $\theta$ is a residual phase shift due to the length of line through the hybrid. The electrical length of the lower path is adjusted to equal $\theta$, so the three relative values of phase are $0^{\circ},-90^{\circ}$ and $+90^{\circ}$ over the bandwidth at the hybrid coupler.

The center conductors at the two open circuited terminal planes were recessed $1.65 \mathrm{~mm}$ to equalize the electrical lengths of the shorted and open paths. The assembled three-position phase shifter is shown in figure 11 . Results of measurements for both the shorted and open conditions relative to the bottom path are shown in figure 12 .

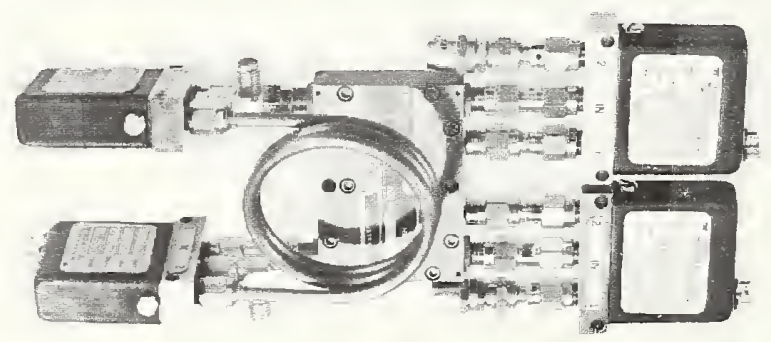

Figure 1l. Photograph of a broadband threeposition phase shifter. 

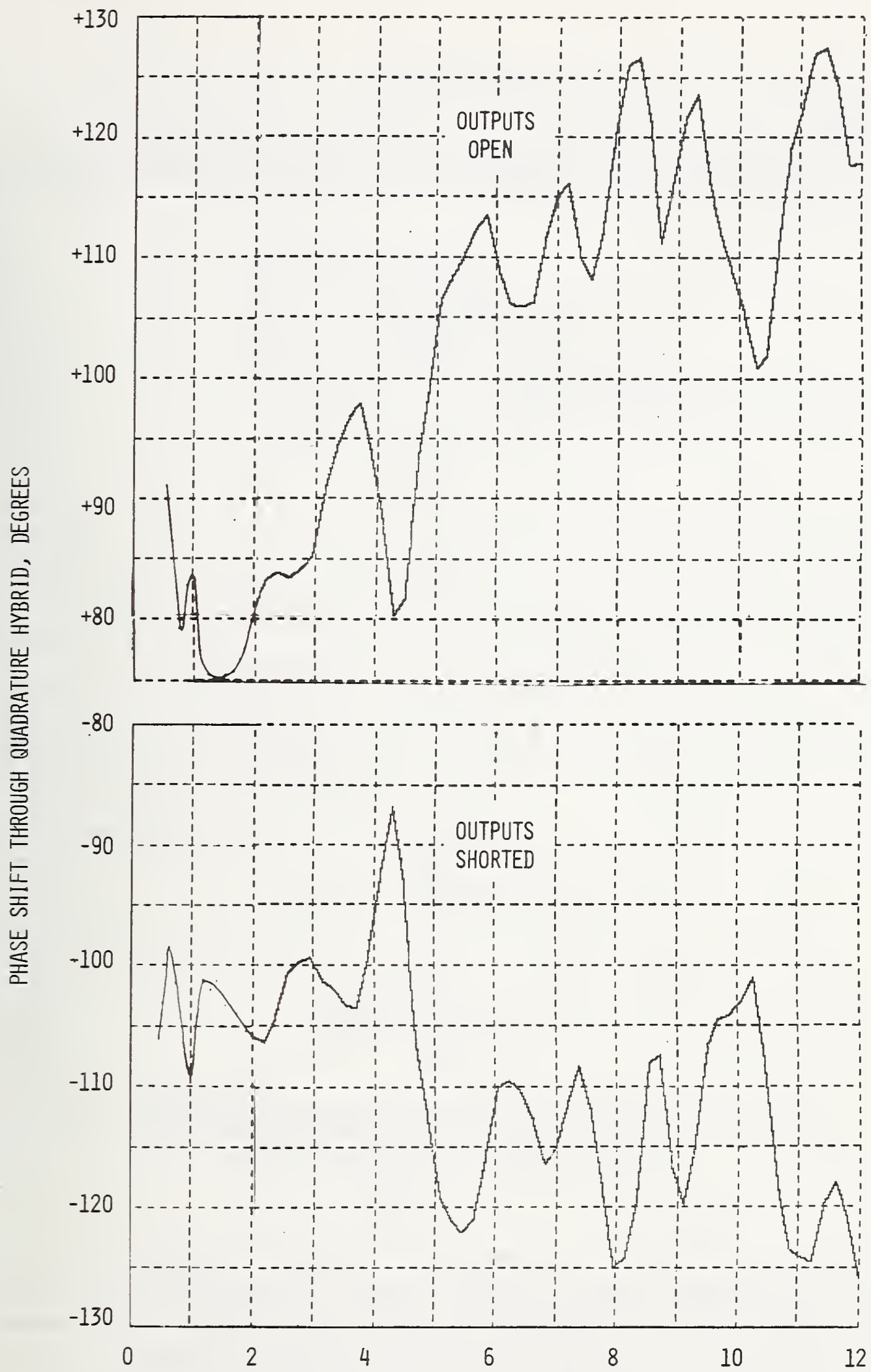

FREQUENCY, GHZ

Figure 12. Phase shift through the quadrature hybrid shown in figure 1 relative to the bottom coax line, measured on the NBS automatic network analyzer. 


\section{Applications}

Several types of measurement can be performed using the MVV. Three types are shown in figure 13. Some additional applications are described in [8] and [9].

(a)

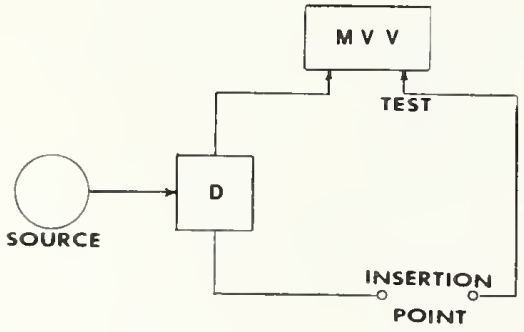

(b)

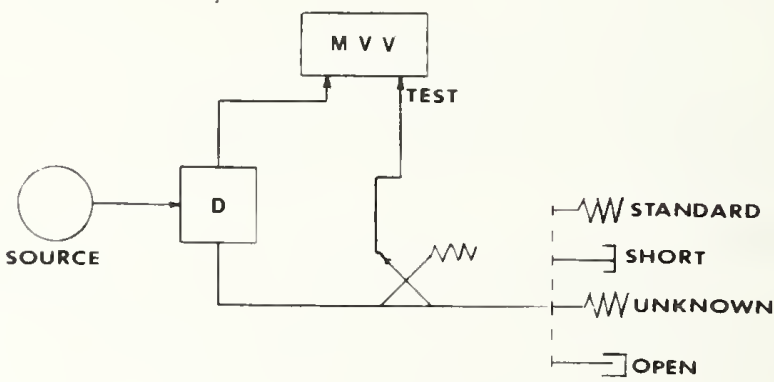

(c)

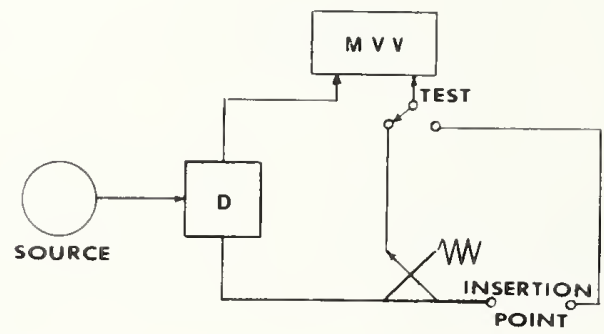

Figure 13. Some measurement configurations using the microwave vector voltmeter. Device $D$ may be either a power divider or a directional coupler.

For the measurement shown in figure $13(\mathrm{a})$, the item under test must be a two-port device or system connected at the insertion point. The measurement configuration shown in figure $13(\mathrm{~b})$ is for one-port devices and the configuration of figure 13 (c) may be used for either one-port or two-port devices. 
Appendix C contains a listing of the program used to calibrate the seven-port junction and make measurements. This program contains a list of eight tasks which can be performed individually or sequentially. These tasks are:

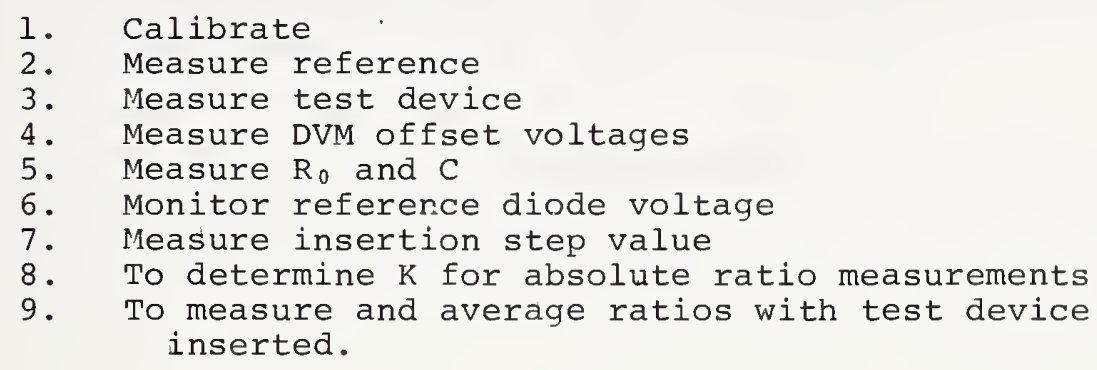

Tasks 1, 2, and 3 are intended to be used most frequently where task 1 (calibrate) must, of course, be used before any measurements are made. Task 2 establishes a reference voltage ratio and task 3 measures a test voltage ratio relative to the reference voltage ratio. Any number of test voltage ratios may be measured relative to a reference or the option exists to reestablish a new reference ratio at any time by selecting task 2. Each time a task is completed the system will pause and wait for a new task selection which may be selected by entering the number of the task at the keyboard followed by an execute command.

The reference ratio is the value

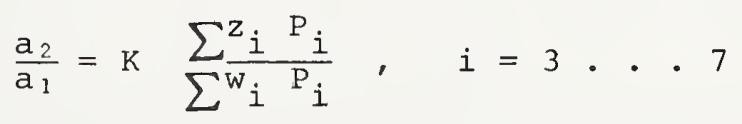

and the test ratio is the value

$$
\frac{\mathrm{a}_{2}^{\prime}}{\mathrm{a}_{1}^{i}}=\mathrm{K} \sum_{\sum_{i}^{\mathrm{z}_{i}} \mathrm{P}_{i}^{\prime}}^{\mathrm{w}_{i}}, \quad i=3 . .7
$$

The insertion ratio $\mathrm{R}$ is computed from these two ratios

$$
R=\frac{a_{2}^{1} / a_{1}^{\prime}}{a_{2} / a_{1}}
$$

Tasks 4 (measure DVM offset voltages), 6 (monitor reference diode voltage), and 7 (measure insertion step value) are available for general information about the complete system in case there is some question about the measurement results. 
Task 5 (measure $\mathrm{R}_{0}$ ) is performed at the end of the calibration procedure automatically, however it may also be performed at any other time when applicable. Its purpose is to establish a zero input reference at the terminal plane of the test device insertion point. Establishing a zero reference value increases the reliability of the measurements for high values of insertion ratio, 40 to $60 \mathrm{~dB}$. The need for this measurement is due to non-ideal isolation between input ports 1 and 2 which allows some of the signal at port 1 to go through the seven-port junction and appear at port 2 . Portions of this leakage signal are then reflected from discontinuities in the transmission line leading from port 2 to the insertion point. The effect of this leakage signal is measured and cancelled out of the measurements of the test signals.

Task 5 also allows the operator to input a value for the absolute power, $\mathrm{P}_{r^{\prime}}$ incident at the input reference terminal of the MVV. Measurement of the incident power can be accomplished using a calibrated bolometer-coupler. The program then calculates a value for $\mathrm{C}$ in

$$
\mathrm{P}_{r}=c \sum_{i=3}^{i=7} w_{i} P_{i}
$$

so that the reference power can be monitored and printed by the calculator. If this is not useful information, simply input $\mathrm{P}_{r}=1$ when the calculator asks for $\mathrm{P}_{r}$ and then. ignore the $\mathrm{P}_{r}$ column. Ratio accuracy is not affected by the value input for $\mathrm{P}_{\mathrm{r}}$.

Task 8 allows $\mathrm{K}$ in (3) to be determined. The operator is instructed to apply two signals equal in amplitude and phase to the test port and to the reference port so that $\mathrm{a}_{2} / \mathrm{a}_{1}=1+j 0$. Other reference ratios of $\mathrm{a}_{2} / \mathrm{a}_{1}$ are then calculated relative to this first one.

Task 9 is a special routine to be used where source power stability is a problem. This task changes the sequence of reading the diode output voltages on the seven-port junction. All diode voltages are measured as fast as possible taking one reading from each diode. The voltage ratio ai/ai is measured 2 to 25 times depending on the value of $\mathrm{K} 6$ in line 5140 of the MVV program. The average ratio is then computed. Results of the measurement are calculated using (5).

\section{OPERATING PROCEDURE}

$\underline{\text { Turn-on }}$

First make sure that excessive microwave power levels are not present which could damage the diode detectors. Fifty milliwatts is considered excessive, however power levels of 10 milliwatt or less are recommended. 
Turn on the ac power switch on the front panel of the voltmeter chassis and the computer and high-speed printer.

The front panel push button controls on the DVM should be set to "DC" and "Futo". The multiplexer push button controls should be set at "PWR", "REM" and "EXT". The multiplexer first point and last point thumbwheel switches should be set to 0 and 30 respectively.

\section{$\underline{\text { Program }}$}

Load the program stored on file 2 of the cassette tape by pressing consecutively:

\section{Load}

2

Execute.

\section{Operating}

When the program has been loaded into computer memory it may be executed by pressing "Run" and "Execute". The computer will display or print questions and instructions. Questions can be answered through the keyboard while instructions can be acknowledged after completion by pressing "Cont" (continue) and "Execute". For example: The first question displayed when running the program is "Frequency (GHz)?" The operator responds by typing the frequency and pressing execute. The computer responds by setting the switches for the correct isolators in the MVV and then lists the eight available tasks on the high-speed printer. The operator may then select the aporopriate task by typing the number of the task and pressing execute.

In general, it is desirable to set the power levels so that the test and reference channel power levels are approximately the same magnitude. The reference channel may be monitored by selecting task 6 and should be set so that the reference diode output level is between 5 and 10 millivolts.

When the frequency is changed the program should be started over (press Run, Execute) so that the isolators will be reset. The system will need to be recalibrated also. The system can be stopped at any time and returned to the "Next operation" question by pressing:

Stop

Cont $\leqslant 00$

Execute. 


\section{ERRORS}

The major sources of error are:

1. Detector nonlinearities

2. Step attenuator nonrepeatability

3. Frequency drift

4. Leakage signals

5. Signal level variation

The following is a description of these errors and of methods used to reduce them.

\section{Detector nonlinearity}

This is the largest single source of error in the MVV. Diode detectors are used because of their small size, availability, simplicity, and ease of instrumentation; however, the output voltage response is not proportional to input power over a wide dynamic range. Some major factors affecting diode response are diode loading impedance and ambient temperature.

To improve the diode response curve each diode detector has an output loading resistor which was selected for the most optimum square-law response by comparing the diode output with known input power levels measured using a bolometer bridge power meter.

In addition, the diodes are temperature controlled to within approximately \pm 0.1 degree Celsius using an aluminum block with a heater and temperature sensor controlled by a proportional oven temperature control circuit.

\section{Step attenuator nonrepeatability}

Self calibration of the seven-port junction is a process where six equations are produced relating the step attenuator value to two groups of power measurements. A basic assumption in solving the six simultaneous equations is that the step attenuator value is the same for each equation. If this is not true then the results may not fit to any lower value of precision than the precision of repeatability of the step attenuator. 
Repeatability tests on the step attenuator produced standard deviations for groups of 10 steps of about $0.001 \mathrm{~dB}$. A major factor which can increase the nonrepeatability is connector loosening due to vibrations from repeated switch closures. To reduce this effect a periodic check using the diagnostic routine (file 4 on cassette tape) is recommended which monitors the step repeatability for groups of five step closures. The connectors on the step may be retightened to improve the repeatability. Do not overtighten, since excessive torque may ruin the connectors on the switches.

\section{Erequency Drift}

Frequency variations from a microwave source will affect any phase measurement in a two-channel system if the two channels do not have equal electrical lengths. For example, a path length difference ( $\Delta d$ ) of one meter in air dielectric coaxial line will result in a phase change $(\Delta P)$ of 12 degrees when the frequency varies by $10 \mathrm{MHz}$. The relationship is

$$
\Delta P=\frac{360 \Delta d \Delta f}{C}
$$

where $\Delta f$ is the frequency variation during the measurement period and $c$ is the velocity of propagation.

Within the MVV, electrical lengths have been equalized for both channels in the measurement and calibration circuits; however, electrical path length differences external to the MVV can contribute to phase changes as well, so this effect must be considered. Both frequency control and equalization of external path lengths are recommended to minimize this source of error.

Leakage Signals

Isolation between the input ports 1 and 2 at the seven-port junction is required so that any change in $\Gamma_{1}$ or $I_{2}$ due to a change in $a_{1}$ or $a_{2}$ is negligible. (See Appendix A, eq. 18).

$$
\frac{V_{2}}{V_{1}}=\frac{a_{2}\left(I+I_{2}\right)}{a_{1}\left(1+I_{I}\right)}
$$

Isolation across the seven-port junction is greater than $40 \mathrm{~dB}$, however this small amount produces significant errors when the measured insertion loss is $40 \mathrm{~dB}$ or greater. This effect has been reduced to approximately $60 \mathrm{~dB}$ by using the "measure $\mathrm{R}_{0}$ " routine described previously in section IV. 
An error can appear in calibration of the seven-port junction if the signal level varies during the time between measurements with the step in and the step out. From Appendix A equation (20)

$$
L=\frac{a_{i}^{\prime}}{a_{2}}=\frac{\sum z_{i} P_{i}^{\prime}}{\sum Z_{i}{ }^{P_{i}}}, i=3 . \cdot 7,
$$

$L$ is the insertion ratio of the two-position insertion step attenuator. A change in signal level from the microwave source between measurements of $a_{2}$ and $a_{2}^{\prime}$ will introduce an error in the calculation of $L$ and therefore an error in the calculation of the seven-port constants. This error will have the same effect as the previously described error from step attenuator nonrepeatability.

\section{EVALUATION}

\section{System Repeatability}

Measurement precision and accuracy may vary from time to time depending on such factors as microwave source stability, step repeatability, and operating power levels. A reliable check on measurement precision appears in sigma of the self-calibration printout. Sigma is the standard deviation of differences between the calculated and measured values of the step attenuator for each of the six calibration measurements. If sigma is less than $0.03 \mathrm{~dB}$ the calibration is good and measurements should repeat to about the same value for insertion ratios up to about $20 \mathrm{~dB}$. Above $20 \mathrm{~dB}$ the errors should increase approximately one order of magnitude for each $20 \mathrm{~dB}$ increment of insertion change in the test channel.

Intercomparison

A measurement comparison between the MVV and the NBS network analyzer has been performed using a $0-70 \mathrm{~dB}$ (10 dB steps) attenuator. Isolators were connected on both sides of the attenuator and measurements were made in the octave frequency range between 4 and $8 \mathrm{GHz}$ using both systems. Results of that intercomparison are given in table I and table II. 
Table I.

Attenuation Measurement Difference (dB)

ANA - MVV

\begin{tabular}{cccccc}
\hline $\begin{array}{c}\text { Frequency } \\
\text { GHz }\end{array}$ & $10 \mathrm{~dB}$ & $20 \mathrm{~dB}$ & $30 \mathrm{~dB}$ & $40 \mathrm{~dB}$ & $50 \mathrm{~dB}$ \\
\hline 4.0 & 0.35 & .07 & .07 & .49 & 1.7 \\
4.5 & 0.27 & .03 & .31 & .07 & 1.1 \\
5.0 & 0.10 & .08 & .06 & .15 & 0.2 \\
5.5 & 0.05 & .04 & .13 & .06 & 0.5 \\
6.0 & 0.02 & .07 & .14 & .41 & 1.5 \\
6.5 & 0.02 & .01 & .00 & .26 & 0.8 \\
7.0 & 0.01 & .05 & .31 & .17 & 0.0 \\
7.5 & 0.01 & .01 & .01 & .11 & 0.6 \\
8.0 & 0.07 & .04 & .32 & .42 & 1.3 \\
\hline
\end{tabular}

Table II.

Phase Shift Measurement Difference (degrees)

ANA - MVV

\begin{tabular}{cccccc}
\hline $\begin{array}{c}\text { Frequency } \\
\mathrm{GHz}\end{array}$ & $10 \mathrm{~dB}$ & $20 \mathrm{~dB}$ & $30 \mathrm{~dB}$ & $40 \mathrm{~dB}$ & $50 \mathrm{~dB}$ \\
\hline 4.0 & 0.6 & 1.1 & 5.7 & 8.6 & 32.3 \\
4.5 & 0.01 & 0.1 & 1.8 & 0.8 & 6.5 \\
5.0 & 0.3 & 0.6 & 0.2 & 6.2 & 10.5 \\
5.5 & 0.3 & 1.1 & 3.9 & 11.2 & 37.8 \\
6.0 & 0.5 & 0.6 & 2.1 & 3.9 & 59.1 \\
6.5 & 0.2 & 0.6 & 0.2 & 1.4 & 1.0 \\
7.0 & 0.5 & 0.5 & 2.2 & 0.3 & 0.3 \\
7.5 & 0.7 & 0.6 & 1.1 & 1.1 & 2.3 \\
8.0 & 0.2 & 0.3 & 7.3 & 2.4 & 3.0 \\
\hline
\end{tabular}


VIII. TROUBLESHOOTING

The following table lists some troubles that may occur during operation of the MVV system, their probable cause and cure.

Those troubles due to malfunctioning commercial equipment contained within the system should be referred to the respective manuals (supplied with the system) covering that equipment.

Trouble

Program won't

converge to

correct solution

in self-calibration

procedure.

Bad data
Probable cause and/or cure

CAUSE: 1. Data incorrect due to power level--too high or too low.

2. Switches not functioning.

3. Data transfer error caused by transient noise or interface cable trouble.

CURE: 1. Compare data with samples of good data that did converge.

2. Check switches by running diagnostic program to measure step repeatability and cycle the switches.

3. Check for adequate signal level in both the reference and test channels in the calibration and measurement modes.

4. Rerun the self-calibration routine.

CAUSE: 1. Equipment not on.

2. Interface cables loose.

3. Scanner not setting correctly.

4. DVM malfunction or controls at wrong setting

5. Attenuators not switching correctly.

6. Switches sticking on phase shifter or repeatable step.

CURE: 1. Check equipment and cables.

2. Cycle switches.

3. Watch scanner during self-calibration routine to see if the scanner is changing channels properly.

4. Check data from the DVM, display data transferred to the computer and make sure it is the same as that displayed on the DVM.

5. Monitor diode voltage levels to see if there is sufficient signal present in both channels in the measurement and calibration modes. 
Improper Switching

Program won't load
CAUSE: 1. Switch sticking

2. Switch driver malfunctioning

3. Interface cable disconnected.

CURE: 1. Cycle switches several times using the diagnostic routines and listen for audible switching noise. If no switches work, check the switch driver, interface cables, and statements in the program which control the switching functions. See Appendix C. If some switches work but others do not the switches may be bad or the driver output power level may be low. If possible substitute switches.

CAUSE: 1. Bad tape

2. Dirt or residue on tape reader

3. Computer out

CURE: 1. Clean the tape reader then reload the program.

2. Load program from another tape.

3. Check computer manual.

\section{BIBLIOGRAPHY}

1. Hoer, C. A., Theory and application of a six-port coupler, NBS report (unpublished).

2. Hoer, C. A., The six-port coupler: A new approach to measuring voltage, current, poirer, impedance, and phase, IEEE Trans. Instrum. Meas., Vol. IM-21, Nov. 1972, p 466-470.

3. Engen, G. F. and C. A. Hoer, Application of an arbitrary six-port junction to power measurement problems, IEEE Trans. Instrum. Meas., Vol. IM-21, Nov. 1972, p 470-474.

4. Hoer, C. A. and G. F. Engen, Analysis of a six-port junction for measuring $v, i, a, b, z, \Gamma$, and phase, presented at the Proc. IMEKO Symp. Acquisition and Processing of Measurement Data for Automation, Dresden, Germany, June 17-23, 1973.

5. Engen, G. F., Calibration of an arbitrary six-port junction for measurement of active and passive circuit parameters, IEEE Trans. Instrum. Meas., Vol. IM-22, Dec. 1973, p 295-299.

6. Hoer, C. A., Using six-port and eight-port junctions to measure active and passive circuit parameters, National Bureau of Standards (U.S.), Tech. Note 673, Sept. 1975, 23 pages.

7. Hoer, C. A. and K. C. Roe, Using an arbitrary six-port junction to measure complex voltage ratios, IEEE Trans. Microwave Theory and Techniques, Vol. MTT-23, No. 12, Dec. 1975, p 978-984.

8. How vector measurements expand design capabilities, Application note 91 , Hewlett-Packard Company, January 1968.

9. Vector voltmeter measurement techniques, Application note 22, PRD Electronics, Inc., May 1971. 

APPENDIX A

\section{USING AN ARBITRARY SIX-PORT JUNCTION}

\section{TO MEASURE COMPLE VOLTAGE RATIOS}

The following report is reproduced in its entirety because it provides the theoretical background for the MVV system. All work in this Appendix and in the main body of the report represents the same effort, therefore repetition can be avoided by referral to portions of this Appendix which cover the applicable subject. 



\title{
Using an Arbitrary Six-Port Junction to Measure Complex Voltage Ratios
}

\author{
CLeTUS A. HOER, member, ieee, and KeI'TH C. ROE, member, ieee
}

\begin{abstract}
An arbitrary six-port junction is analyzed as a microwave vector voltmeter, measuring the amplitudes and phase differences of two input signals in terms of power readings taken at the remaining four ports. The junction may be calibrated for measuring the complex ratio of these two signals using a self-calibration procedure which requires no attenuation or phase standards.
\end{abstract}

Manuseript received April 14, 1975. This work was partially supported by the Naval Sea Systems Command, USAFSAM, and the Army Metrology and Calibration Center. This is a contribution of the National Bureau of Standards not subject to copyright.

The authors are with the National Bureau of Standards, Boulder, Colo. 80302 .

\section{INTRODUC'YION}

DERHAPS the greatest impact in the fich of IHI and microwave measurement in recent years has bern the introduction of the automatie notwork andyzer (ANA). In contrast with the prior art where the key to improved accuracy was usually an improved hardware item, the procedure now is to measure the hardware inperfections and adjust the measurement results in such a way as to account for them. The key to this correction process is in the measurement of the phase as well as 
amplitude of the complex parameters involved. The measurement of this phase has generally involved conversion to a lower frequency which complicates the detection process. Although phase detection circuits which operate at microwave frequencies are well known, these have generally assumed ideal components, and are not particularly suitable for automation.

Recent theoretical studies of an arbitrary six-port have provided an alternative method of obtaining the phase information without requiring either frequency conversion or ideal components. [1], [2], [7]. One of the unexpected results of this study is that most of the earlier six-port designs for getting phase information provide a set of data which is ill conditioned from the viewpoint of the more general theory. Fortunately, the theory also suggests how to design the six-port junction to eliminate this condition.

This paper shows how the ratio of two complex voltages or two complex wave amplitudes can be measured using an arbitrary six-port junction where four of the ports are terminated with power meters. If two coherent signals of the same frequency are applied to the remaining two ports, the junction gives the phase angle between the two signals as well as the amplitude of both in terms of the four power meter readings. The six-port junction thus hecomes a vector voltmeter in which phase and amplitude information are calculated from power measurements.

The six-port junction can be calibrated for making complex ratio measurements without using any standards. The only precision component needed in the calibration or measurement setup is a two-position step attenuator whose change in insertion ratio must be highly repeatable, but need not be known. Its value is determined in the calibration process along with other unknown constants deseribing the six-port. The complete calibration process is readily automated, requiring no operator involvement.

Accuracy of ratio measurements is determined primarily by the linearity of the four detectors. Precision components are not required to make precise ratio measurements.

The analysis of a six-port junction as a vector voltmeter is similar to that of a six-port junction used for power [1] or impedance [2] measurements.

\section{(iENERAL THEORY}

('onsider an arbitrary six-port junction shown in Fig. 1, where four ports are terminated with power meters. If the junction is linear and only one mode is present at

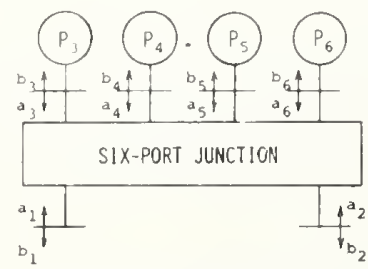

Fig. 1. An arbitrary six-port junction with power meters on four of the six ports. each port, the scattering equations for the junction can be written

$$
b_{i}=\sum_{j=1}^{6} S_{i j} a_{j}, \quad i=1 \cdots 6
$$

where $a_{j}$ and $b_{i}$ are the complex incident and emergent wave amplitudes and the $S_{i j}$ are the scattering parameters of the junction. Assuming that the power meters on arms $3 \cdots 6$ are permanently connected

$$
a_{j}=b_{j} \Gamma_{j}, \quad j=3 \cdots 6
$$

where $\Gamma_{j}$ is the reflection coefficient of the power meter on port $j$. Equations (1) and (2) represent a collection of ten linear equations in terms of the twelye variables $a_{i}, b_{i}, i=1 \cdots 6$. This system of equations may be solved for any ten of these variables as functions of the remaining two. In particular, it is possible to write

$$
b_{i}=A_{i} a_{1}+B_{i} a_{2}, \quad i=3 \cdots 6
$$

where $A_{i}$ and $B_{i}$ are functions of the scattering parameters of the junction and the reflection coefficients of the power meters. Multiplying (3) by its complex conjugate yields

$$
\begin{aligned}
\left|b_{i}\right|^{2}=\left|A_{i}\right|^{2}\left|a_{1}\right|^{2}+ & A_{i} B_{i}{ }^{*} a_{1} a_{2}{ }^{*}+A_{i}{ }^{*} B_{i} a_{1}{ }^{*} a_{2} \\
& +\left|B_{i}\right|^{2}\left|a_{2}\right|^{2}, \quad i=3 \cdots 6
\end{aligned}
$$

where $(*)$ indicates complex conjugate.

If the phase angles $\phi_{1}, \phi_{2}$, and $\phi$ are defined such that

$$
a_{1}=\left|a_{1}\right| \exp \left(j \phi_{1}\right), \quad a_{2}=\left|a_{2}\right| \exp \left(j \phi_{2}\right)
$$

and

$$
\phi=\phi_{2}-\phi_{1}
$$

then (4) becomes

$$
\begin{array}{r}
\frac{P_{i}}{K_{i}}=\left|A_{i}\right|^{2}\left|a_{1}\right|^{2}+\left(A_{i} B_{i}{ }^{*}+A_{i}{ }^{*} B_{i}\right)\left|a_{1} a_{2}\right| \cos \phi \\
+\left|B_{i}\right|^{2}\left|a_{2}\right|^{2}+j\left(A_{i}{ }^{*} B_{i}-A_{i} B_{i}{ }^{*}\right)\left|a_{1} a_{2}\right| \sin \phi, \\
i=3 \cdots 6
\end{array}
$$

where $P_{i} \equiv K_{i}\left|b_{i}\right|^{2}$ is the power indicated by the meter on the $i$ th port, and $K_{i}$ is a constant. This expression represents a linear system of four equations in the four unknowns $\left|a_{1}\right|^{2},\left|a_{2}\right|^{2},\left|a_{1} a_{2}\right| \cos \phi$, and $\left|a_{1} a_{2}\right| \sin \phi$. If these equations are independent ${ }^{1}$ they may be inverted to obtain each of the four unknowns as a linear function of the four $P_{i}(i=3 \cdots 6)$. The result is

$$
\begin{aligned}
\left|a_{1}\right|^{2} & =\sum \rho_{i} P_{i} \\
\left|a_{2}\right|^{2} & =\sum \sigma_{i} P_{i}, \quad i=3 \cdots 6 \\
\left|a_{1} a_{2}\right| \cos \phi & =\sum x_{i} P_{i} \\
\left|a_{1} a_{2}\right| \sin \phi & =\sum y_{i} P_{i}
\end{aligned}
$$

${ }^{1}$ It is this condition that is not satisfied by most older six-port designs used for getting phase information from amplitude measurements. See the section on "Six-Port Design Criteria." 
where each sum in (7) and throughout this paper is over the four sidearm power readings, $i=3 \cdots 6$. The coefficients of $P_{i}$ are real numbers which are functions of the parameters $S_{i j}$ and $\Gamma_{j}$. Equations ( 7 ) constitute the desired result and are valid for any linear six-port junction subject to the conditions mentioned. The ratio $a_{2} / a_{1}$ can be written

$$
\frac{a_{2}}{a_{1}}=\frac{\left|a_{2}\right|}{\left|a_{1}\right|} \exp (j \phi)=\frac{\left|a_{1} a_{2}\right|}{\left|a_{1}\right|^{2}}(\cos \phi+j \sin \phi) .
$$

Using (7) this becomes

$$
\frac{a_{2}}{a_{1}}=\frac{\sum\left(x_{i}+j y_{i}\right) P_{i}}{\sum \rho_{1} P_{i}}
$$

A more useful form of (9) for calibration purposes is obtained by factoring $x_{m}+j y_{m}$ out of the top sum and factoring $\rho_{n}$ out of the bottom sum to get

$$
\frac{a_{2}}{a_{1}}=K \frac{\sum z_{i} P_{i}}{\sum w_{i} P_{i}}
$$

where

$$
\begin{aligned}
& K=\frac{x_{m}+j y_{m}}{\rho_{n}} \\
& z_{i}=\frac{x_{i}+j y_{i}}{x_{m}+j y_{m}} \\
& w_{i}=\frac{\rho_{i}}{\rho_{n}}
\end{aligned}
$$

and where $m$ and $n$ can each be either $3,4,5$, or 6 . For many applications the complex constant $K$ does not need to be known. Since $z_{i}=1$ when $i=m$, and $w_{i}=1$ when $i=n$, this leaves only three complex $z_{i}$ and three real $w_{i}$ to be determined.

\section{COMPLEX VOLTAGE RATIOS}

The voltage at the two input ports can be written

$$
\begin{aligned}
v_{i} & =a_{i}+b_{i}, \quad i=1,2 \\
& =a_{i}\left(1+\Gamma_{i}\right)
\end{aligned}
$$

where $\Gamma_{i}$ is the complex ratio $b_{i} / a_{i}$ at port $i$

$$
\begin{aligned}
& \Gamma_{1}=S_{11}+S_{12} \frac{a_{2}}{a_{1}} \\
& \Gamma_{2}=S_{22}+S_{21} \frac{a_{1}}{a_{2}} .
\end{aligned}
$$

The scattering parameters in (16) and (17) are those of the equivalent two-port which results when the four sidearms of the six-port junction are terminated with power meters. The ratio of the two input voltages is

$$
\frac{v_{2}}{v_{1}}=\frac{a_{2}\left(1+\Gamma_{2}\right)}{a_{1}\left(1+\Gamma_{1}\right)} .
$$

The voltage ratio will be proportional to $a_{2} / a_{1}$ provided that there is sufficient isolation between input ports 1 and 2 so that any change in $\Gamma_{1}$ or $\Gamma_{2}$ due to a change in $a_{1}$ or $a_{2}$ is negligible.

\section{SELF-CALIBRATION PROCEDURE}

All of the constants in (10) except $K$ can be determined by a self-calibration technique which does not require any standards. The technique is based on earlier work described by Allred and Manney [3]. A calibration circuit such as shown in Fig. 2 is used. A signal is divided into two channels which are connected to the inputs of the six-port junction. The signal $a_{1}$ in one channel is held constant by internally leveling the generator and isolating it from the signal $a_{2}$ in the other channel which contains a level set attenuator $\alpha_{0}$, phase shifter $\phi_{0}$, and a twoposition insertion device. Data for calibrating the six-port junction are obtained by noting the value of all $P_{i}$ for the two positions of the insertion device at different settings of $\alpha_{0}$ and $\phi_{0}$. The value of the insertion device does not need to be known, but it must be highly reproducible and independent of signal level.

The initial value of $a_{2}$ relative to $a_{1}$ is determined by the setting of $\alpha_{0}$ and $\phi_{0}$, which also need not be known. When the insertion device is switched to its second position, $a_{2}$ changes to $a_{2}^{\prime}$ and the power readings change from $P_{i}$ to $P_{i}^{\prime}$. Assuming that $a_{1}$ is constant during the time it takes to read the $P_{i}$ and $P_{i}{ }^{\prime},(7 a)$ and (13) give

$$
\sum w_{i} P_{i}=\sum w_{i} P_{i}^{\prime} \text {. }
$$

The ratio of $a_{2}{ }^{\prime} / a_{2}$ obtained from (10) is

$$
L \equiv \frac{a_{2}^{\prime}}{a_{2}}=\frac{\sum z_{i} P_{i}^{\prime}}{\sum z_{2} P_{i}} .
$$

This $L$ is the change in insertion ratio of the two-position insertion device. The ratio of $\left|a_{2}{ }^{\prime}\right|^{2} /\left|a_{2}\right|^{2}$ obtained from (7b) is

$$
|L|^{2}=\frac{\sum u_{i} P_{i}^{\prime}}{\sum u_{i} P_{i}}
$$

where $u_{i} \equiv \sigma_{i} / \sigma_{l}$ and $l$ is either $3,4,5$, or 6 . Since $u_{l}=1$, there are only three $u_{i}$ to be determined in (21).

The measurements of $P_{i}$ and $P_{i}^{\prime}$ are repeated for four

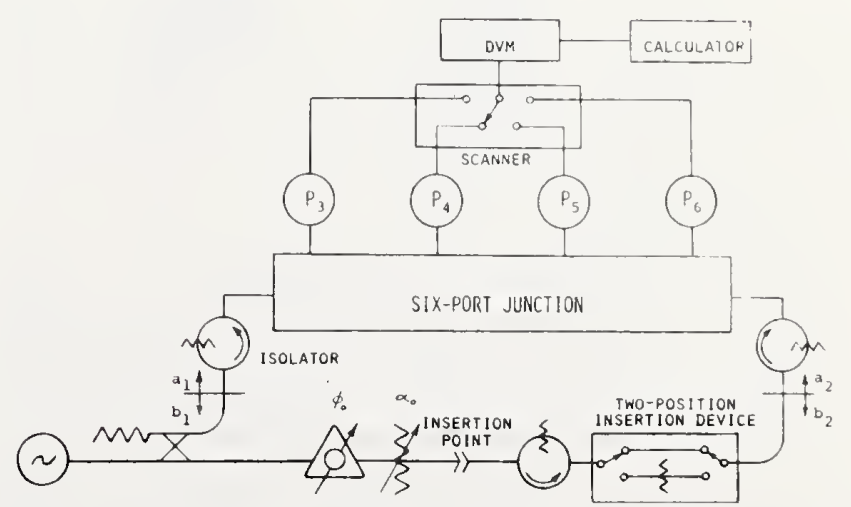

Fig. 2. Setup for calibrating and using a six-port junction to measure complex voltage ratios. 
or more different settings of $\alpha_{0}$ and $\phi_{0}$. Each different setting gives additional equations like (19)-(21), where $L$ is the same for each measurement. These three sets of equations can be solved for the calibration constants $z_{i}$, $w_{i}$, and $u_{i}$ and also for $L$.

To assure that $L$ remains constant when $\alpha_{0}$ and $\phi_{0}$ are changed, and that $a_{1}$ remains constant at the two positions of $L$, isolators are added as shown in Fig. 2. Further analysis may show that not all of the isolators are needed.

\section{CALCULATING SIX-PORT CONSTANTS}

When the complex insertion ratio $L$ is known, it can be thought of as a ratio standard in calibrating the six-port junction to obtain the constants $z_{i}, w_{i}$, and $u_{i}$. However, it is not necessary that $L$ be known; $L$ can be treated as simply one more unknown constant to be determined. When $L$ is not known, (20) is a nonlinear equation which can be solved by writing it in the form

$$
f=\sum z_{i}\left(L P_{i}-P_{i}{ }^{\prime}\right)=0
$$

and expanding $f$ in a Taylor series about the best estimates of $z_{i}$ and $L$

$$
f \simeq f_{0}+\sum_{i \neq m} \frac{\partial f}{\partial z_{i}} \Delta z_{i}+\frac{\partial f}{\partial L} \Delta L_{i}=0
$$

where $f_{0}$ is the value of $f$ calculated from (22) using best estimates of $z_{i}$ and $L$. The partial derivatives

$$
\begin{aligned}
& \frac{\partial f}{\partial z_{i}}=L P_{i}-P_{i}^{\prime} \\
& \frac{\partial f}{\partial L}=\sum z_{2} P_{i}
\end{aligned}
$$

are also calculated using best estimates of $z_{i}$ and $L$.

Initial estimates of $z_{i}$ to use in (25) and in calculating $f_{0}$ can be determined by solving (22) for the $\tilde{z}_{i}$ using an estimate of $L$ as a known value. A set of four or more equations like (23), which is linear in the unknowns $\Delta z_{i}$ and $\Delta L$, is solved for these four unknowns which are then used to improve the estimates of $z_{i}$ and $L$

$$
\begin{aligned}
& \text { new } Z_{i}=\text { old } Z_{i}+\Delta Z_{i} \\
& \text { new } L=\text { old } L+\Delta L \text {. }
\end{aligned}
$$

These new estimates of $z_{i}$ and $L$ are used in (23) and the iteration repeated until the $\Delta$ 's become insignificant. Once $L$ is determined, (21) becomes linear in the three unknown $u_{i}$ so that three or more equations like (21) can be solved directly for the $u_{i}$.

The constants $\rho_{n}, \sigma_{l}$, and $x_{m}+j y_{m}$ cannot be determined by this calibration process. However, for measuring complex insertion ratios, these constants are not needed. Complex insertion ratios of $a_{2}^{\prime} / a_{2}$ can now be measured using the known $z_{i}$ in (20). If only the amplitude of $L$ is desired, it is somewhat simpler to calculate $|L|^{2}$ using the real $u_{2}$ in (21) rather than the complex $z_{i}$ in (20). Using tho $z_{i}$ and $w_{i}$ in (10), ratios of $a_{2} / a_{1}$ can be measured to within a constant $K$.

\section{BROAD-BAND TWO-POSITION INSERTION DEVICE}

In calibrating the six-port junction, the complex insertion ratio $L$ of the repeatable two-position insertion device must not have a phase angle of $0^{\circ}$ or multiples of $90^{\circ}$. A phase shift of $45^{\circ}$ is probably optimum. One way of getting $45^{\circ}$ phase shift over a broad frequency range is shown in Fig. 3. The two outputs of the quadrature hybrid $(Q)$ are equal in amplitude but $90^{\circ}$ out of phase. Adding these two signals with an in-phase power divider $(D)$ gives a signal that is shifted $45^{\circ}$ relative to the input signal. In addition to this $45^{\circ}$ there will be some phase shift $\theta$ due to the lengths of line. The length of the lower path can be adjusted to give a phase shift equal to $\theta$. The phase difference in the two switch positions will be $45^{\circ}$ over the complete frequency range of the hybrid and divider, which can be the same as the frequency range of the six-port. The amplitude of the insertion ratio will be $3 \mathrm{~dB}$.

The optimum value of $|L|$ has not been determined. Values near 3 and $8 \mathrm{~dB}$ have been used with no noticeable difference in results.

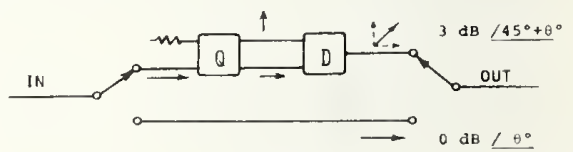

Fig. 3. Using a quadrature hybrid $(Q)$ and a power divider $(D)$ to make an insertion ratio of $3 \mathrm{~dB}$ with $45^{\circ}$ phase shift.

\section{SIX-PORT DESIGN CRITERIA}

As one might expect, not all six-port junctions are equally useful in making measurements of $\left|a_{1}\right|,\left|a_{2}\right|$, and $\phi$. One useful design is an extension of the phase discriminator or correlator circuit which is a six-port device often used to get phase information from amplitude measurements [4]. Fig. 4 shows a correlator constructed from three quadrature hybrids and one in-phase power divider. If the components are ideal, the phase angle is calculated from $P_{5} \ldots P_{8}$ using

$$
\begin{aligned}
4\left|a_{1} a_{2}\right| \cos \phi & =\left|a_{1}+a_{2}\right|^{2}-\left|a_{1}-a_{2}\right|^{2} \\
& =k\left(P_{5}-P_{7}\right) \\
4\left|a_{1} a_{2}\right| \sin \phi & =\left|a_{1}-j a_{2}\right|^{2}-\left|a_{1}+j a_{2}\right|^{2} \\
& =k\left(P_{6}-P_{8}\right)
\end{aligned}
$$

Fig. 4. A correlator constructed from one power divider $(D)$ and three quadrature hybrids $(Q)$. Ideal components would give outputs proportional to the values shown. 
where $k$ is a constant. Although the correlator is a six-port device, the equations in (7) do not apply in the limit when the correlator becomes ideal because the four outputs are not linearly independent. The identity

$$
\left|a_{1}+a_{2}\right|^{2}+\left|a_{1}-a_{2}\right|^{2}=\left|a_{1}-j a_{2}\right|^{2}+\left|a_{1}+j a_{2}\right|^{2}
$$

shows that the correlator has only three independent outputs since any one output can be obtained from the other three. In a sense, the correlator by itself is only a fiveport junction. One more independent output must be added to the correlator to have (7) apply. Since the correlator alone cannot give $\left|a_{1}\right|^{2}$ and $\left|a_{2}\right|^{2}$ which do come out of (7), we might expect that adding an output proportional to $\left|a_{1}\right|^{2}$ or $\left|a_{2}\right|^{2}$ would make a valid set of four independent outputs. This is indeed the case. Fig. 5 shows a correlator with two power dividers and two more detectors added to make $\left|a_{1}\right|^{2}$ and $\left|a_{2}\right|^{2}$ available. The six outputs are listed in Table I. It can be shown that a set of four independent outputs is obtained by choosing one from each group in Table I, plus a fourth output which can be any one of the six not already chosen. For example, if $\left|a_{1}\right| \simeq\left|a_{2}\right|$, a six-port vector voltmeter could have outputs approximately proportional to

$$
\left|a_{1}\right|^{2}, \quad\left|a_{1}+a_{2}\right|^{2}, \quad\left|a_{1}-j a_{2}\right|^{2}, \quad\left|a_{2}\right|^{2} .
$$

Or if $\left|a_{2}\right| \ll\left|a_{1}\right|$ one might design the outputs to approximate

and

$$
\left|a_{1}\right|^{2}, \quad\left|a_{1}+a_{2}\right|^{2}, \quad\left|a_{1}-j a_{2}\right|^{2}
$$

$$
\left|a_{1}-a_{2}\right|^{2}
$$

or

$$
\left|a_{1}+j a_{2}\right|^{2} \text {. }
$$

Here $\left|a_{1}-a_{2}\right|^{2}$ or $\left|a_{1}+j a_{2}\right|^{2}$ is used instead of $\left|a_{2}\right|^{2}$ because $\left|a_{2}\right|^{2}$ might be too small to measure, but $\left|a_{1}-a_{2}\right|^{2}$ or $\left|a_{1}+j a_{2}\right|^{2}$ would still contain useful information about $a_{2}$.

As with other six-port applications, the outputs listed

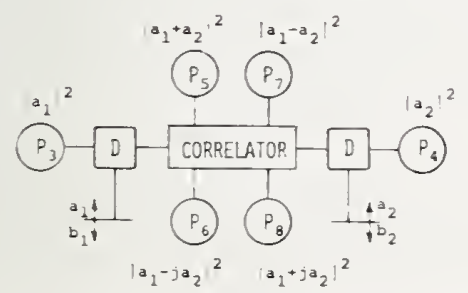

Fig. 5. Adding two power dividers $(D)$ to a correlator to make an eight-port junction having several combinations of four independent outputs.

TABLE I

\begin{tabular}{c|c|c}
\hline GROUP 1 & GROUP 2 & GROUP 3 \\
\hline$\left|a_{1}\right|^{2}$ & $\left|a_{1}+a_{2}\right|^{2}$ & $\left|a_{1}-j a_{2}\right|^{2}$ \\
$\left|a_{2}\right|^{2}$ & $\left|a_{1}-a_{2}\right|^{2}$ & $\left|a_{2}+j a_{2}\right|^{2}$ \\
\hline
\end{tabular}

Note: A set of four independent outputs is obtained by choosing one from each group plus a fourth which can be any one of the six not already chosen. in Table I are only design goals. The actual outputs of a six-port junction can depart considerably from these values and still be quite useful. For example, the output $\left|a_{1}+j a_{2}\right|^{2}$ indicates that ideally $a_{1}$ and $a_{2}$ would be $90^{\circ}$ apart at detector 8. But the output is still useful even though the phase difference is $\pm 60^{\circ}$ from the ideal $90^{\circ}$. When the outputs depart greatly from those in Table I, the coefficients of $P_{i}$ in (7) become large so that the desired information is obtained from the difference between large terms in the sum. As the individual terms in the sum become significantly larger than the quantity on the left of the corresponding equa sign in (7), greater precision is required in measuring each $P_{i}$ to obtain a given accuracy.

\section{EXPERIMENTAL SETUP}

An eight-port junction following the design shown in Fig. 5 was constructed from commercially available miniature coaxial $X$-band components with SMA connectors. This was converted to a six-port by terminating ports 7 and 8 with $50-\Omega$ loads so that the remaining four outputs are approximately proportional to those in (33). A photograph of the junction is shown in Fig. 6. The components in the photograph are identified in Fig. 7 which also shows how the signals are combined to get the desired outputs. Four diode-type power meters having a linearity of \pm 1 percent from $10 \mathrm{nW}$ to $10 \mu \mathrm{W}$ were used as detectors. The power level into each diode was kept less than $10 \mu \mathrm{W}$ to assure square-law operation.

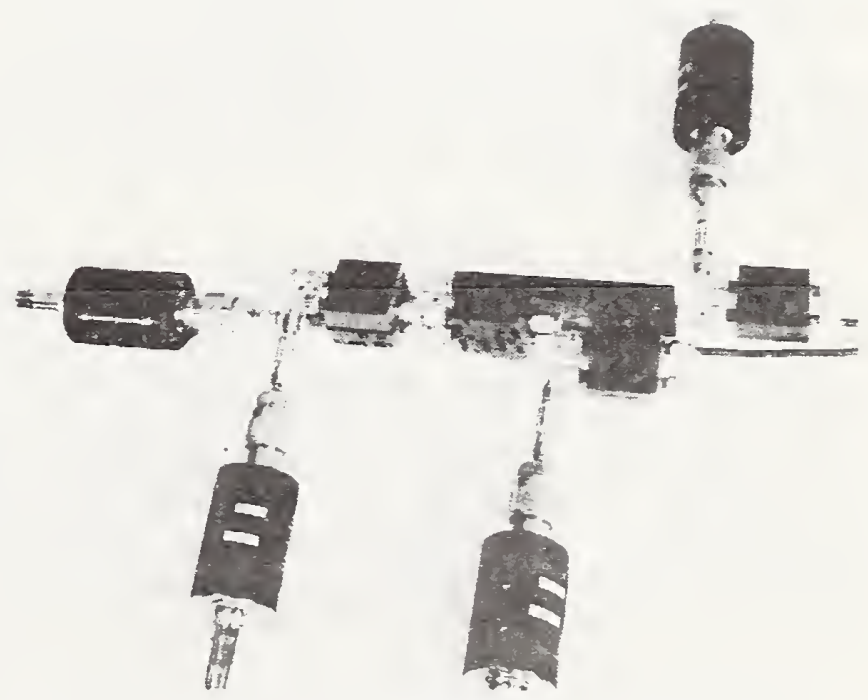

Fig. 6. Experimental six-port junction and power detector mounts.

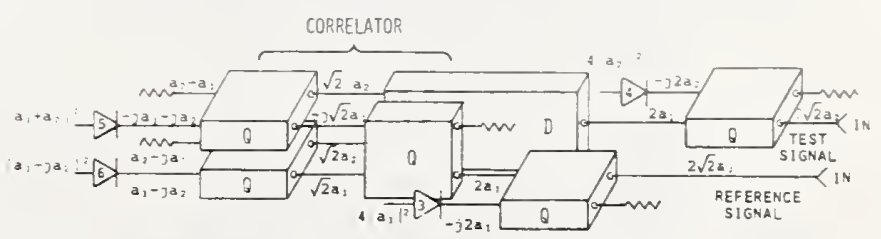

Fig. 7. Identifying the components in Fig. 6, where $Q$ indicates quadrature hybrids, and $D$ indicates an in-phase power divider. The signals labeled at different parts of the circuits are those obtained from ideal components if the two input signals are $2 \sqrt{2} a_{1}$ and $2 \sqrt{2} a_{2}$. 


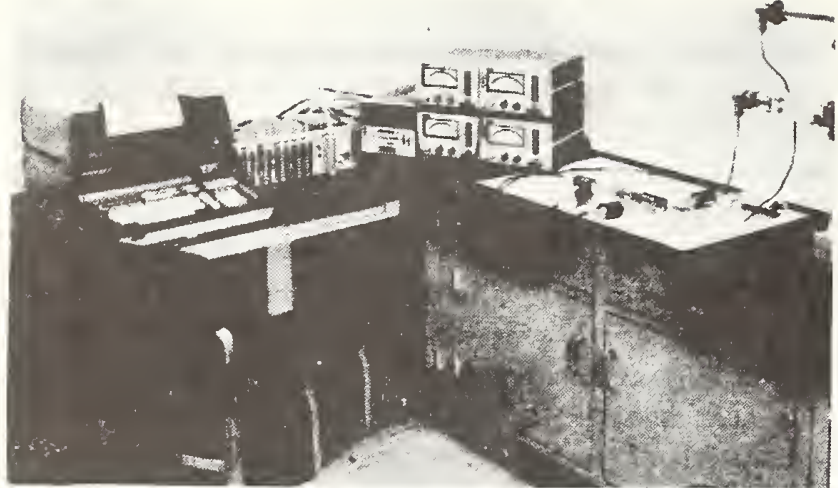

Fig. 8. Experimental six-port $X$-band vector voltmeter setup. From left to right: programmable calculator,'input/output expander, DVM and scanner, four-power meters, six-port junction (on white paper), and two-input signal lines.

Since the six-port calibration and measurement process requires taking many sidearm power measurements, it is most desirable to have the data read directly into a computer which can then process the data. A programmable calculator is capable of taking the necessary sidearm power readings under program control, and then processing the data to give the calibration constants and measurement results.

Basic language programs have been written for calibrating the junction as a microwave vector voltmeter, and also for using it to measure complex insertion ratio. After calibrating the six-port junction using the setup in Fig. 2, the same setup is used to measure complex insertion ratios by either changing or inserting something in the test (lower) channcl, and using (20) to calculate the ratio.

A picture of the setup is shown in Fig. 8. The same setup can be used with any type power detectors that have an output de voltage which is a known function of the input power level.

\section{RESULTS}

Preliminary measurements have been made on this setup at $8-12 \mathrm{GHz}$. The complex insertion ratio of the twoposition step attenuator $L$, was measured with the sixport junction and then measured by the National Bureau of Standards ANA. The results are shown in Table II. The agreement is within what one would expect using detectors linear to only 1 percent. Better power detectors should give greater accuracy. The comparison shows that the theory of using an arbitrary six-port junction as a

TABLE II

Amplitude and Phase Change in the Two-Position Step Attenuator as Measured by the Six-Port with Diode Power Meters and by the National Bureau of STANDARDS ANA

\begin{tabular}{|c|c|c|c|c|c|}
\hline \multirow{4}{*}{ 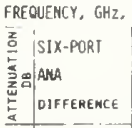 } & 8 & 9 & 10 & 11 & 12 \\
\hline & 7.82 & 7.58 & 7.52 & 7.91 & 8.53 \\
\hline & 7.75 & 7.57 & 7.4 & 7.9 & 8.36 \\
\hline & .07 & .01 & .04 & -.01 & .17 \\
\hline \multirow{3}{*}{$\begin{array}{l}\text { SIX-PORT } \\
\text { ALA } \\
\text { DIFFERENCE }\end{array}$} & 38. & 34. & 33. & 31.49 & 31.00 \\
\hline & 38.09 & 34,81 & 32.45 & 31.73 & 30.91 \\
\hline & .06 & -.68 & .74 & -.24 & .09 \\
\hline
\end{tabular}

Note: Six-port versus ANA. vector voltmeter is correct. It also shows that the sixport junction can be calibrated without using any standards. The only precision component in the setup is the two-position step attenuator whose change in insertion ratio is repeatable to $\pm 0.001 \mathrm{~dB}$.

\section{O'THER APPLICATIONS}

Once the six-port vector voltmeter has been calibrated, it can be used to measure the complex reflection coefficient of a one-port device by using it on the sidearms of a reflectometer. The setup in Fig. 2 can be converted to a reflectometer by inserting a directional coupler at the "insertion point" as shown in Fig. 9. The resulting reflectometer can be calibrated to measure $\Gamma$ at the reference plane using established techniques [5], [6]. If it is desired to measure only $\Gamma$ with the setup, the six-port vector voltmeter can be calibrated as before with the directional coupler permanently fixed at the insertion point. A sliding short at the reference plane could then take the place of $\phi_{0}$. The reflection coefficient is calculated from

$$
\Gamma=\frac{A\left(a_{2} / a_{1}\right)+B}{1+C\left(a_{2} / a_{1}\right)}
$$

where $A, B$, and $C$ are complex constants. Note that although $K$ in (10) is not known, it can be thought of as being part of $A$ and $C$ which are determined in calibrating the reflectometer. It is, therefore, not necessary to know $K$ for this application. If the only application of the sixport junction is to measure $\Gamma$, it is probably better to calibrate the junction directly as a reflectometer using other techniques which do not require isolators [7].

\section{DISCUSSION}

The experimental system described here could be simplified to make a relatively inexpensive automatic measurement system of moderate accuracy. The six-port component and diode detectors could be fabricated in one stripline package. Since measurements are made directly at the test frequency, no local oscillator (LO) or phaselocked sources are required to heterodyne the signal to some lower frequency. The six-port concepts should be useful into the millimeter-wave region where it becomes difficult to measure phase by other techniques. The complete calibration process can be controlled by a programmable calculator or small computer.

Accuracy of the six-port measurements is determined primarily by the linearity of the detectors. Bolometricor thermoelectric-type power detectors would give greater accuracy than that achieved in our experiment, but that

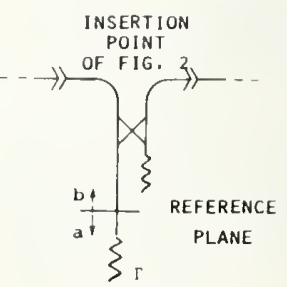

Fig. 9. Adding a directional coupler to the setup in Fig. 2 to make complex reflection coefficient measurements. 
would increase the measurement time somewhat. Another approach to increased accuracy would be to model the diodes and mathematically correct for their nonlinearity with the computer. This latter approach is presently under investigation.

\section{ACKNOWLEDGMENT}

The authors wish to thank C. M. Allred for assistance in working out the self-calibration techniques. They also wish to thank G. F. Engen for his helpful discussions throughout the project.

\section{REFERENCES}

(1) G. F. Engen and C. A. Hoer, "Application of an arbitrary 6-port junction to power-measurement problems," IEEE Trans. Instrum. Meas. (1972 Conferecne on Precision Electromagnetic
Measurements), vol. IM-21, pp. 470-474, Nov. 1972.

[2] C. A. Hoer and G. F. Engen, "Analysis of a six-port junction for measuring $v, i, a, b, z, \Gamma$, and phase," presented at the Proc. IMEKO Symp. Acquisition and Processing of Measurement Data for Automation, Dresden, Germany, June 17-23, 1973.

[3] C. M. Allred and C. H. Manney, "Self-calibration of complex ratio measuring systems," presented at the Proc. IMEKO Symp. Acquisition and Processing of Measurement Data for Automation, Dresden, Germany, June 17-23, 1973.

[4] S. B. Cohn and N. P. Weinhouse, "An automatic microwave phase measurement system," Microwave $J$., vol. 7, pp. 49-56, Feb. 1964 .

[5] R. A. Hachborn, "An au'omatic network analyzer system," Microwave J., vol. 11, pp. 45-62, May 1968.

[6] G. F. Engen, "Calibration technique for automated network analyzers with application to adaptor evaluation," IEEE Trans. Microwave Theory Tech. (Parl II of Two Parls), vol. MTT-22, pp. 1255-1260, Dec. 1974.

[7] 1 , "Calibration of an arbitrary six-port junction for measurement of active and passive circuit parameters," IEEE Trans. Instrum. Meas. (Special Issue on 1973 EEMTIC and IM Symposium). vol. IM-22, pp. 295-299, Dec. 1973. 


\title{
APPENDIX B
}

\section{CONTROL COMMANDS USED IN THE COMPUTER}

\author{
OPERATING PROGRAM
}

The following tables list commands that are used in the operating programs to control specific functions in the microwave vector voltmeter. These commands are located in various parts of the program listed in Appendix C. Use of these tables is intended to be an aid in understanding the program and in writing other software routines or modifyjing existing routines.

\section{IMPORTANT NOTICE}

Certain commercial equipment is identified in this report. This does not imply endorsement by the National Bureau of Standards nor does it imply that the equipment identified is necessarily the best available for the purpose. 
Control Commands from Computer to MVV

Effect

Insertion Step Out

Insertion Step In

Phase Shifter $+90^{\circ}$

Phase Shifter $-90^{\circ}$

Phase Shifter $0^{\circ}$

Switches 2, 4, 5 to D

Switches 2, 4, 5, to S

Switches 1, 3, 6, 7 to $\mathrm{C}$

Switches $1,3,6,7$ to $M$
Device under Control

Scanner Model 1200

Driver 120-1

Scanner Mode1 1200

Driver 120-1

Scanner Mode1 1200

Driver 120-1

Scanner Mode1 1200

Driver 120-1

Scanner Mode1 1200

Driver 120-1

Scanner Mode1 1200

Driver 120-1

Scanner Model 1200

Driver 120-1

Scanner Model 1200

Driver 120-1

Scanner Model 1200

Driver 120-1

Scanner Mode1 1200

Driver 120-1

Scanner Mode1 1200

Driver 120-1
Command

Write $(1, *)$ WBYTE 47 ;

Write $(2, *)$ WBYTE 1 ;

Write $(1, *)$ WBYTE 46 ;

Write $(2, *)$ WBYṬE ${ }^{\circ} 1$;

Write $(1, *)$ WBYTE 43 ;

Write $(2, *)$ WBYTE 1 ;

Write $(1, *)$ WBYTE 45 ;

Write $(2, *)$ WBYTE 1 ;

Write $(1, *)$ WBYTE 43 ;

Write $(2, *)$ WBYTE 1 ;

Write $(1, *)$ WBYTE 44 ;

Write $(2, *)$ WBYTE 1 ;

Write $(1, *)$ WBYTE 42 ;

Write $(2, *)$ WBYTE 1 ;

Write (1*) WBYTE 41; Write $(2, *)$ WBYTE 1 ;

Write $(1, *)$ WBYTE 40 ; Write $(2, *)$ WBYTE 1 ;

Write $(1, *)$ WBYTE 39 ; Write $(2, *)$ WBYTE 1 ;

Write $(1, *)$ WBYTE 38 ; Write $(2, *)$ WBYTE 1 ; 
Control Commands from Computer to MVV

Effect

Device under Control

Commanả

Test Atten: $0 \mathrm{db}$

$1 \mathrm{db}$

$2 \mathrm{db}$

$3 \mathrm{db}$

$4 \mathrm{db}$

$5 \mathrm{db}$

$6 \mathrm{db}$

$7 \mathrm{db}$

$8 \mathrm{db}$

$9 \mathrm{db}$

$10 \mathrm{db}$

$11 \mathrm{db}$

$12 \mathrm{db}$

$13 \mathrm{db}$

$14 \mathrm{db}$

$15 \mathrm{db}$

Reference

Atten: $5 \mathrm{db}$

$10 \mathrm{db}$

$15 \mathrm{db}$

\begin{tabular}{|c|c|}
\hline$\underset{\|}{\text { Driver }}$ & ${ }_{11}^{120-1}$ \\
\hline$"$ & $"$ \\
\hline 11 & $" 1$ \\
\hline$"$ & " \\
\hline " & " \\
\hline$"$ & " \\
\hline 11 & $" 1$ \\
\hline 11 & $"$ \\
\hline "1 & 11 \\
\hline 11 & $"$ \\
\hline " & " \\
\hline 11 & $"$ \\
\hline " & " \\
\hline 11 & 11 \\
\hline$" 1$ & " \\
\hline
\end{tabular}

Write $(2, \stackrel{*}{*})$ WBYTE ( $\phi$ or 1$)$; " $(2$ or 3$)$; "1" $"(4$ or 5$)$; " " " $(6$ or 7$)$; " " " (8 or 9); " " " (10 or 11); " " " (12 or 13); " " " (14 or 15); " " " $" 16$ or 17$)$; " " " (18 or 19); " " " (20 or 21);

" " " (22 or 23);

" " " (24 or 25$)$;

" " " (26 or 27);

" " " (28 or 29);

" " " (30 or 31);

$\begin{array}{lllll}" 1 & 11 & 1 & (32 \text { or } 33) ; \\ " & 11 & 11 & (64 \text { or } 65) ; \\ " & 11 & 11 & (96 \text { or } 97) ;\end{array}$


Control Commands from Computer to MVV

Effect Device under Contro1 Command

Isolators to $8-12 \mathrm{GHz}$

Isolators to $4-8 \mathrm{GHz}$

Isolators to $2-4 \mathrm{GHz}$

Isolators to $.5-2 \mathrm{GHz}$

Take Voltage Readings from the 5 detectors in the MVV

$\begin{array}{lll}\text { Scanner Mode1 } & 1200 \\ \text { Driver } & 120-1 & \\ \text { Scanner } & \text { Mode1 } & 1200 \\ \text { Driver } & 120-1 & \\ \text { Scanner Mode1 } & 1200 \\ \text { Driver } & 120-1 & \\ \text { Scanner Mode1 } & 1200 \\ \text { Driver } & 120-1 & \end{array}$

Scanner Mode1 1200 Driver 120-1

Scanner Mode1 1200

Driver 120-1

Scanner Mode1 1200-1

Driver 120-1

Scanner Mode1 1200-1

Driver 120-1

Scanner Model 1200-1

Driver 120-1

Scanner Model 1200-1

Driver 120-1

Scanner Mode1 1200-1

Driver 120-1

Scanner Mode1 1200-1

Driver 120-1

Scanner Mode1 1200

Driver 120-1

Scanner Model 1200

Driver 120-1

Scanner Mode1 1200

Driver 120-1

Scanner Mode1 1200

Driver 120-1

Scanner Mode1 1200

DVM Model 3500

Scanner Model 1200

DVM Mode1 3500

Scanner Mode1 1200

DVM Mode1 3500

Scanner Mode1 1200

DVM Model 3500

Scanner Model 1200

DVM Mode1 3500
Write $(1, *)$ WBYTE 31 ;

Write $(2, *)$ WBYTE 1 ;

Write $(1, *)$ WBYTE 26 ;

Write $(2, *)$ WBYTE 1 ;

Write $(1, *)$ WBYTE 25 ;

Write $(2, *)$ WBYTE 1 ;

Write $(1, *)$ WBYTE 22 ;

Write $(2, *)$ WBYTE 1 ;

Write $(1, *)$ WBYTE 30 ;

Write $(2, *)$ WBYTE 1 ;

Write $(1, *)$ WBYTE 29 ;

Write $(2, *)$ WBYTE 1 ;

Write $(1, *)$ WBYTE 24 ;

Write $(2, *)$ WBYTE 1 ;

Write $(1, *)$ WBYTE 23;

Write $(2, *)$ WBYTE 1 ;

Write $(1, *)$ WBYTE 30 ;

Write $(2, *)$ WBYTE 1 ;

Write $(1, *)$ WBYTE 28 ;

Write $(2, *)$ WBYTE 1 ;

Write $(1, *)$ WBYTE 24 ;

Write $(2, *)$ WBYTE 1 ;

Write $(1, *)$ WBYTE 22;

Write $(2, *)$ WBYTE 1 ;

Write $(1, *)$ WBYTE 31 ; Write $(2, *)$ WBYTE 1 ;

Write $(1, *)$ WBYTE 27 ;

Write $(2, *)$ WBYTE 1 ;

Write $(1, *)$ WBYTE 25 ;

Write $(2, *)$ WBYTE 1 ;

Write $(1, *)$ WBYTE 23 ;

Write $(2, *)$ WBYTE 1 ;

Write $(1, *)$ WBYTE 58 ;

Enter $(4, *)$ A, B

Write $(1, *)$ WBYTE 59 ;

Enter $(4, *)$ A, B

Write $(1, *)$ WBYTE 60 ;

Enter $(4, *) \mathrm{A}, \mathrm{B}$

Write $(1, *)$ WBYTE 61;

Enter $(4, *)$ A, B

Write $(1, *)$ WBYTE 62 ;

Enter $(4, *) \mathrm{A}, \mathrm{B}$ 
APPENDIX C

COMPUTER PROGRAM DESCRIPTION AND

LISTING WITH SAMPLE PRINTOUT

$-37-$ 


\section{Appendix C}

Computer program description and listing.

Equations (22) - (27) in Appendix A are solved using matrix algebra. Before expressing these equations in matrix notation, add a subscript $j$ to indicate the measurement number, where $j=1 \ldots 6$ in the present calibration routine which takes six measurements. Equation (22) of Appendix A then becomes

$$
f_{j}=\sum_{i=1}^{5}\left(L P_{j i}-P_{j i}^{\prime}\right) z_{i}=0
$$

Subscript $i$ refers to the detector numbers which are relabeled $1 \ldots 5$ in the program. The following table relates the detector number used by the program to that shown in Figure 3 .

Table $\mathrm{C}-1$

\begin{tabular}{|c|c|}
\hline Computer Number & Figure 3 \\
\hline 1 & $P_{3} \alpha\left|a_{1}\right|^{2}$ \\
2 & $P_{5} \alpha\left|a_{1}+a_{2}\right|^{2}$ \\
3 & $P_{8} \alpha\left|a_{1}+j a_{2}\right|^{2}$ \\
4 & $P_{6} \alpha\left|a_{1}-j a_{2}\right|^{2}$ \\
5 & $P_{7} \alpha\left|a_{1}-a_{2}\right|^{2}$ \\
\hline
\end{tabular}

In matrix notation $(\mathrm{C}-1)$ becomes

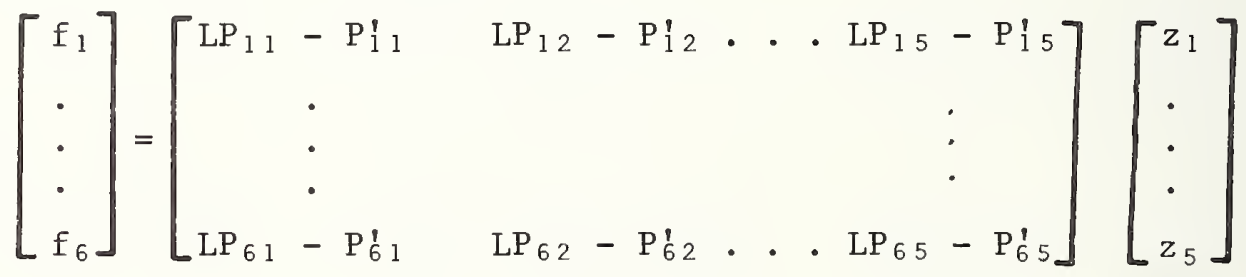


Since $L$ and $z_{i}$ are complex numbers, all matrices in (C-2) are complex. Let $L=L_{1}+j L_{2}$ and $z_{i}=x_{i}+j y_{i}$ where $L_{1}, L_{2}$, and $x_{i}$ and $y_{i}$ are real numbers. Write $(\mathrm{C}-2)$ as

$$
F_{O}=[P+j Q][X+j Y]
$$

where $\mathrm{F}_{\mathrm{O}}$ is a complex matrix but $\mathrm{P}, \mathrm{Q}, \mathrm{X}$, and $\mathrm{Y}$ are real matrices;

$$
\begin{aligned}
& P=\left[\begin{array}{cccc}
\mathrm{L}_{1} \mathrm{P}_{11}-\mathrm{P}_{11}^{\prime} & \ldots & \mathrm{L}_{1} \mathrm{P}_{15}-\mathrm{P}_{15}^{\prime} \\
\cdot & & \cdot \\
\cdot & & \cdot \\
\mathrm{L}_{1} \mathrm{P}_{61}-\mathrm{P}_{61}^{\prime} & \ldots & \mathrm{L}_{1} \mathrm{P}_{65}-\mathrm{P}_{65}^{\prime}
\end{array}\right], Q=\left[\begin{array}{ccc}
\mathrm{L}_{2} \mathrm{P}_{11} & \ldots & \mathrm{L}_{2} \mathrm{P}_{15} \\
\cdot & & \vdots \\
\cdot & & \cdot \\
\cdot & & \\
\mathrm{L}_{2} \mathrm{P}_{61} & \ldots & \mathrm{L}_{2} \mathrm{P}_{65}
\end{array}\right] \\
& \mathrm{X}=\left[\begin{array}{c}
\mathrm{x}_{1} \\
\cdot \\
\cdot \\
\mathrm{x}_{5}
\end{array}\right], \quad \mathrm{Y}=\left[\begin{array}{c}
\mathrm{y}_{1} \\
\dot{\cdot} \\
\mathrm{y}_{5}
\end{array}\right]
\end{aligned}
$$

The $P$ and $Q$ matrices can be written

$$
\mathrm{P}=\mathrm{L}_{1} \mathrm{O}-\mathrm{I}, \quad \mathrm{Q}=\mathrm{L}_{2} \mathrm{O}
$$

Where the O matrix contains the data with the step "out", and the I matrix contains the data with the step "in" (3 dB inserted).

$$
O=\left[\begin{array}{ccc}
\mathrm{P}_{11} & \ldots & \mathrm{P}_{: 5} \\
\cdot & & \cdot \\
\cdot & & \cdot \\
\mathrm{P}_{61} & \ldots & \mathrm{P}_{65}
\end{array}\right], \quad I=\left[\begin{array}{ccc}
\mathrm{P}_{11}^{\prime} & \ldots & \mathrm{P}_{15}^{\prime} \\
\dot{0} & & \dot{\cdot} \\
\dot{\mathrm{P}_{6}} & \ldots & \dot{P}_{65}^{\prime}
\end{array}\right]
$$

The program first takes the data to fill in the 0 and I matrices. It then asks for an estimate of $\mathrm{L}$ (approximately $-3 \mathrm{~dB}$ and 45 degrees) from which it calculates $L_{1}$ and $L_{2}$. The $P$ and $Q$ matrices in $(C-4)$ are then calculated. 
Initial estimates of the $z_{i}$ are obtained by solving (C-1) using the estimated value of $\mathrm{L}$. Since any one of the $z_{i}$ can be set equal to 1 , we choose to set $z_{5}=1+j 0$ since this tends to simplify the mathematics. Equation $(\mathrm{C}-1)$ then becomes

$$
\sum_{i=1}^{4}\left(L P_{j i}-P_{j i}^{\prime}\right) z_{i}=-\left(L P_{j 5}-P_{j 5}^{\prime}\right)
$$

In matrix notation this becomes

$$
\left[\begin{array}{cccc}
\mathrm{LP}_{11}-\mathrm{P}_{11}^{\prime} & \ldots & \mathrm{LP}_{14}-\mathrm{P}_{14}^{\prime} \\
\cdot & & \cdot \\
\mathrm{LP}_{61}-\mathrm{P}_{61}^{\prime} & \ldots & \mathrm{LP}_{64}-\mathrm{P}_{64}^{\prime}
\end{array}\right]\left[\begin{array}{c}
\mathrm{z}_{1} \\
\cdot \\
\cdot \\
z_{4}
\end{array}\right]=-\left[\begin{array}{c}
\mathrm{LP}_{15}-\mathrm{P}_{15}^{\prime} \\
\cdot \\
\cdot \\
\mathrm{LP}_{65}-\mathrm{P}_{65}^{\prime}
\end{array}\right]
$$

Let $\mathrm{N}, \mathrm{Z}$, and $\mathrm{R}$ be the three complex matrices in (C-9) so that (C-9) becomes

$$
\mathrm{NZ}=\mathrm{R}
$$

Note that $N$ is identical to $P+j Q$ if the last column of $P+j Q$ is deleted. The column matrix $R$ is the negative of the last column of $P+j Q$. Since $N$ is not a square matrix, it cannot be inverted. To solve (C-10), first premultiply by $N$ transpose to get

$$
\mathrm{N}^{\top} \mathrm{NZ}=\mathrm{N}^{\top} \mathrm{R}
$$

Since $\mathrm{N}^{\top} \mathrm{N}$ is a square matrix, it can be inverted to give

$$
Z=\left(N^{\top} N\right)^{-1} N^{\top} R
$$

The elements of $z$ are only estimates of the $z_{i}$ since in general $L$ used in $\mathrm{C}-9$ is not known. The correct values of the $z_{i}$ are obtained by using the estimates in equation (23) of Appendix A. 
Adding a subscript $j$ to (23) of Appendix A gives

$$
f_{j}=f_{0 j}+\sum_{i=1}^{4} \frac{\partial f_{j}}{\partial z_{i}} \Delta z_{i}+\frac{\partial f j}{\partial L} \Delta L=0
$$

The sum in $(C-13)$ is from 1 to 4 since $z_{5}=1+j 0$. In matrix notation $(\mathrm{C}-13)$ becomes

$$
-\left[\begin{array}{c}
f_{01} \\
\cdot \\
\cdot \\
f_{06}
\end{array}\right]=\left[\begin{array}{ccccc}
\frac{\partial f_{1}}{\partial z_{1}} & \frac{\partial f_{1}}{\partial z_{2}} & \cdots & \frac{\partial f_{1}}{\partial z_{4}} & \frac{\partial f_{1}}{\partial L} \\
\cdot & \cdot & & \cdot & \cdot \\
\cdot & \cdot & & \cdot \\
\frac{\partial f_{6}}{\partial z_{1}} & \frac{\partial f_{5}}{\partial z_{2}} & \cdots & \frac{\partial f_{6}}{\partial z_{4}} & \frac{\partial f_{6}}{\partial I}
\end{array}\right]\left[\begin{array}{c}
\Delta z_{1} \\
\cdot \\
\cdot \\
\Delta z_{4} \\
\Delta L
\end{array}\right]
$$

where from (24) and (25) of Appendix A

$$
\begin{aligned}
& \frac{\partial f_{j}}{\partial z_{i}}=L P_{j i}-P_{j i}^{\prime} \\
& \frac{\partial f}{\partial I}=\sum_{i=1}^{5} z_{i} P_{j i}
\end{aligned}
$$

Let $F_{0}, M$, and $i Z$ be the three complex matrices in (C-14) so that (C-14) becomes

$$
-F_{0}=M Z
$$

Substituting $(\mathrm{C}-15)$ and $(\mathrm{C}-16)$ in $(\mathrm{C}-14)$ shows that $\mathrm{M}$ is identical to $P+j Q$ except for the last column which contains the $\partial f_{j} / \partial L$. These terms are calculated from (C-16) which can be written

$$
\frac{\partial f}{\partial L}=\sum_{i=1}^{5} P_{j i}\left(x_{i}+j y_{i}\right)
$$


or

$$
\begin{aligned}
{\left[\begin{array}{c}
\frac{\partial f_{1}}{\partial L} \\
\dot{L_{f}} \\
\frac{\partial f_{6}}{\partial L}
\end{array}\right] } & =\left[\begin{array}{ccc}
P_{11} & \ldots & P_{15} \\
\cdot & \\
\cdot & \\
P_{61} & \ldots & P_{65}
\end{array}\right]\left[\begin{array}{c}
x_{1}+j y_{1} \\
\cdot \\
x_{5}+j y_{5}
\end{array}\right] \\
& =0[x+j Y]
\end{aligned}
$$

Therefore $\mathrm{M}$ is obtained by substituting the complex column matrix (C-20) in column 5 of the $P+j Q$ matrix.

Initial estimates of $z_{i}$ to use in calculating $F_{0}$ and $M$ are obtained from (C-12). With these estimates, $F_{0}$ and $M$ can be calculated so that (C-17) can be solved for $\Delta Z$. The solution is

$$
\Delta Z=-\left(M^{\top} M\right)^{-1} M^{\top} F_{0}
$$

The elements of $\Delta \mathrm{Z}$ are used to correct the estimated values of $\mathrm{z}_{1}$ and $\mathrm{L}$;

$$
\begin{aligned}
& \text { new } z_{i}=\operatorname{old} z_{i}+\Delta z_{i} \\
& \text { new } L=\operatorname{old} L+\Delta L
\end{aligned}
$$

The iteration is now repeated, calculating a new $P$ and $Q$ matrix using the new $L$, and calculating a new $F_{0}$ and $M$ matrix using the new $z_{i}$. Then (C-2I) is solved to get a new $\Delta \mathrm{Z}$. The iteration continues until $\Delta \mathrm{L}_{1}<10^{-6}$. Usually $\Delta \mathrm{L}_{1}$ will be less than $10^{-6}$ after four iterations.

Equation (19) of Appendix A is also solved using matrix algebra, but no iteration is required. Adding a subscript $j$ to indicate the measurement number as before, that equation becomes

$$
\sum_{i=1}^{5} w_{i}\left(P_{j i}-P_{j i}^{\prime}\right)=0
$$


For an ideal seven-port junction, all of the $\mathrm{w}_{i}=0$ except for the $\mathrm{w}$ corresponding to $P_{3}$ in figure 3 . Since $P_{3}$ is on channel 非 1 , we choose $w_{1}=1$ in the program. Therefore $(\mathrm{C}-24)$ becomes

$$
\sum_{i=2}^{5} w_{i}\left(P_{j i}-P_{j i}^{\prime}\right)=P_{j 1}^{\prime}-P_{j 1}
$$

which can be written

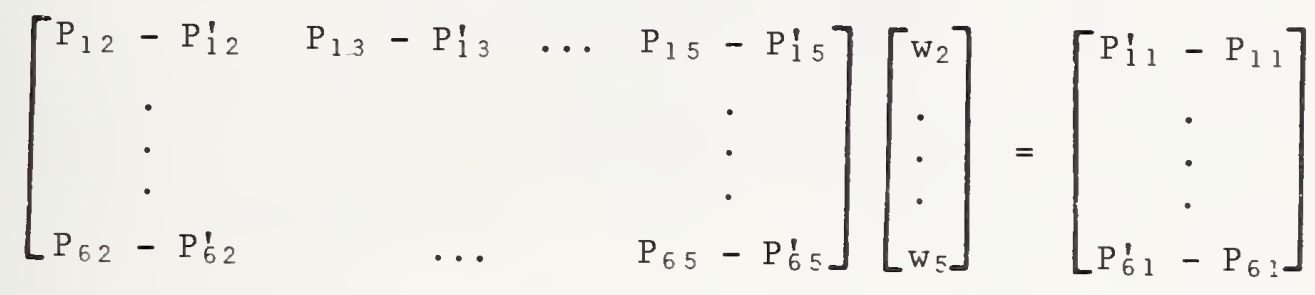

or simply

$$
\mathrm{DW}=\mathrm{C}
$$

whose solution is

$$
W=\left(D^{\top} D\right)^{-1} D^{\top} C
$$




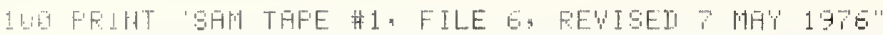

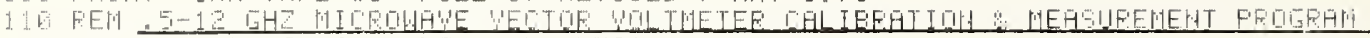

115 FEM SAME HE FILE 2 EUT MITH QFTIOH 9 HIIEI

11. FE' Fil

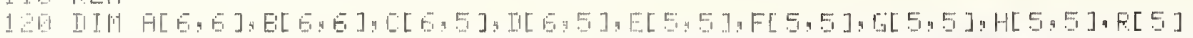

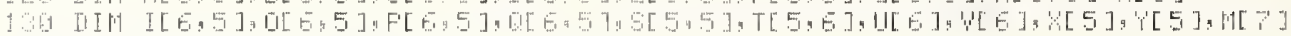

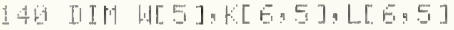

$1567=59$

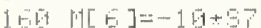

$17+1+5]=-161605$

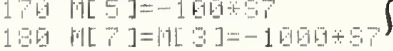

19 IIEG

Scale factor to keep determinants reasonable

ZUE FETH

21日 FFIHT

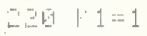

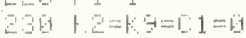

$24+5+5$

25 II ISF

2E IHFIT F

270 TDSUE 2650

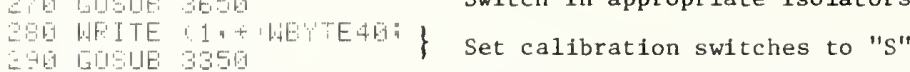

3610 FFI IHT

31 FFIAT

LIS FE H HT

3 FIFIHT

24 FF IHT

SEF FIAT

IE PFIHT

GEF FHT

3itit FIFIHT

195 FFIH

396 FEIHT

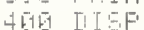

41 IPAFIT 19

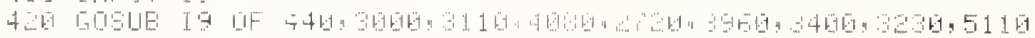

450

EHTEF: 1 TU CHLIEFHIE WEITOF: WOLTMETEF"

EHTEF 2 TI NEHSIFE FEFLEFHE FATIG"

EHTEF 3 TO MEASIAEE FHTIO WITH TEST IEUIDE IHSEFTED

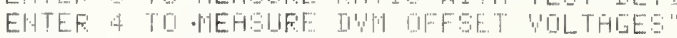

EHTEE 5 TO MEHSUEE FI

EHTEF TL MOHITIF REFEFEHE TIGIE

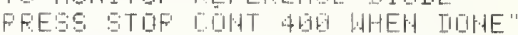

EHTEF $\rightarrow$ TO MEHSIFE STEF WHLUE L

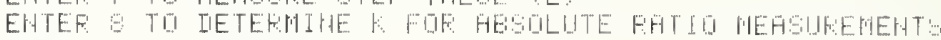

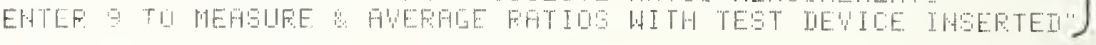

Instructions

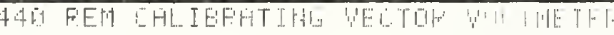

$4561=5$

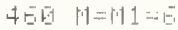

$\mathrm{N}=$ number of diodes used

$M=$ number of measurements made during calibration

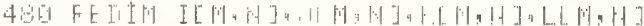

4 IIHT I I = ZEF

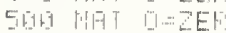

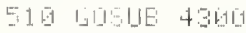

5 GE

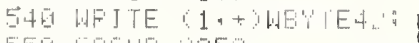

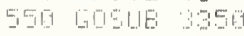

SEl $I=1$

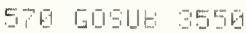

GE WFITE I $14+9$ HEITE 43

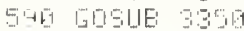

EHG WFTE $14+1$ WEITE45

5.

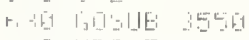

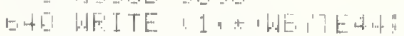

E5E GBSE 3356

$E$ EI $I:=$

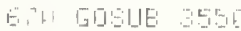

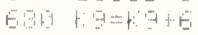

Fit $T=4$

PGE IDINE 55

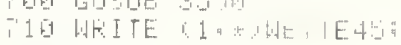

OL IOIE 935

$I=5$

4

T5E WFITE 1

FE FDUE GD

$P 71$ I $I=1$

PGE IDSUE 255

$796+9=0$

1616

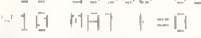

$19+1$
0

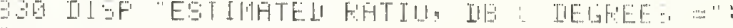

G4G IHFUT L:T

$856=16+L$

EE L $L=L+L O B T$

G $\mathrm{G} L \mathrm{~L}=\mathrm{L}+\mathrm{SIHT}$

Set switches to calibration mode

Read diode offset voltages

Set phase shifter to $\phi^{\circ}$

Take data for measurement 非

Set phase shifter to $\pm 90^{\circ}$ position

Set phase shifter to $+90^{\circ}$

Take data for measurement 非 2

Set phase shifter to $-90^{\circ}$

Take data for measurement 非 3

Add $3 \mathrm{~dB}$ to measurement channel

Take data for measurement 非 4

Set phase shifter to $+90^{\circ}$

Take data for measurement 非

\} Set phase shifter to $0^{\circ}$

Take data for measurement 非 6

\} Take out a11 attenuation in measurement channel

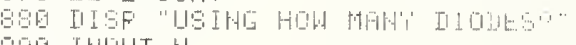

BE IHFUT H

B. $+41=1+1$

$\mathrm{N}=4$ or 5 diodes can be used

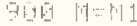


910 FEM IDHLDITLATE THE WRI

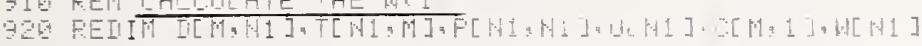

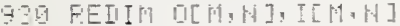

940 LOGUE $498 \mathrm{BO}$

Put calibration data in 0 and I matrices

GEG FOF $\quad I=1$ TI $m$

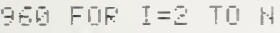

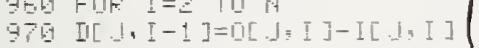

GQW HEST I

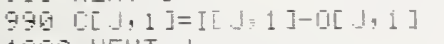

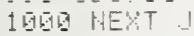

1 G1G MAT T=TFH: II

1020 MAT $F=T+I$

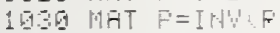

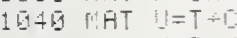

I 1550 GHT

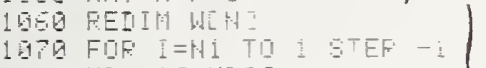

$100 \mathrm{H} H[\mathrm{I}+\mathrm{I}]=\omega[\mathrm{I}]$

1 G日. HEYT I

11 GG WL $1=1$

1129 IF 1130 THEN $19 \mathrm{G}$ Calculate initial estrmate of the $z_{i}$

114 GEIHT $\cdots$ (n)

Caculate $D$ and $C$ matrices

1150 G0T0 +170

11 G FFIHT

117 FF IHT

11 GO FEM I EFATIOH EESTHE

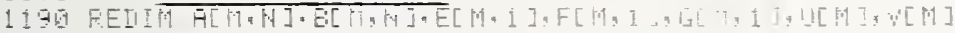

120 WFT $\mathrm{H}=\mathrm{F}$

1210 MAT $E=12$

1220 1018 2019

1200 MHT $U=E$

1240 HAT. $:=F$

Calculate $F_{0}=(P+j Q)(X+j Y)$, store $1 n E+j F$

IEST FEIII C.

$12 T$ HHT $I=0 \quad$ M except for last column

1260 MHT $E=0 \div \div$

1299 MFT $F=[1+1$

\}ast column of $\mathrm{M}$

$130, F[F: I=1$ TI

$1310 \quad[I ; A]=E[I, 1$

$1320 I I I, H]=F[I:-$

133 HE I I

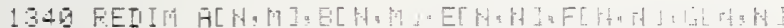

1350 MHT $A=T F H E$ \} $M^{\top}$ stored in $A+j B$

13E MHT E=TFH I:

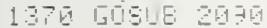

1350 GOE

Calculate $M^{\top} M$, store in $E+j F$

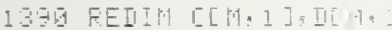

1409 FIAT $\bar{D}=$

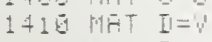

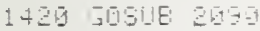

\} Put $F_{0}$ in $C+j D$

Calculate $\left(M^{\top} M\right)^{-1}$, store in $S+j T$

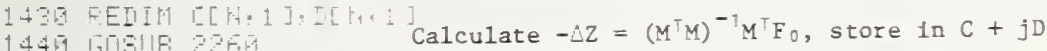

1450 FLE I=1 TL H

$14 E$ WFITE $15,1526,1,1]$

1479 HE T T

1486 FIF $I=1 \quad T I H$

1490 WFITE (15,15.

15 G NEXT I

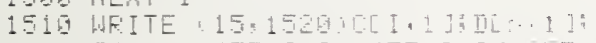

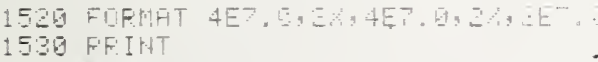

$15+Q-1=L 1-L[F=1 Z\} \quad$ New $L=01 d L+L L$

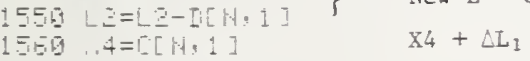

1579 HAT $r=x-1$

1589 HAT $\mathrm{I}=\mathrm{Y}-\mathrm{I}$

1590 WAT $=0$

$1 \mathrm{BM} M \mathrm{MHT} \quad \mathrm{Y}=\mathrm{I}$

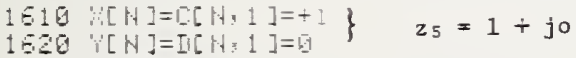

1636 Dosue 4906

$1 E 4$ IF HE 4 1E-GE THE 1140

1650 FFI

If $\Delta \mathrm{L}_{1}>10^{-6}$ then continue 1terating

New $z_{1}=$ old $z_{1}+\Delta z_{1}$ 


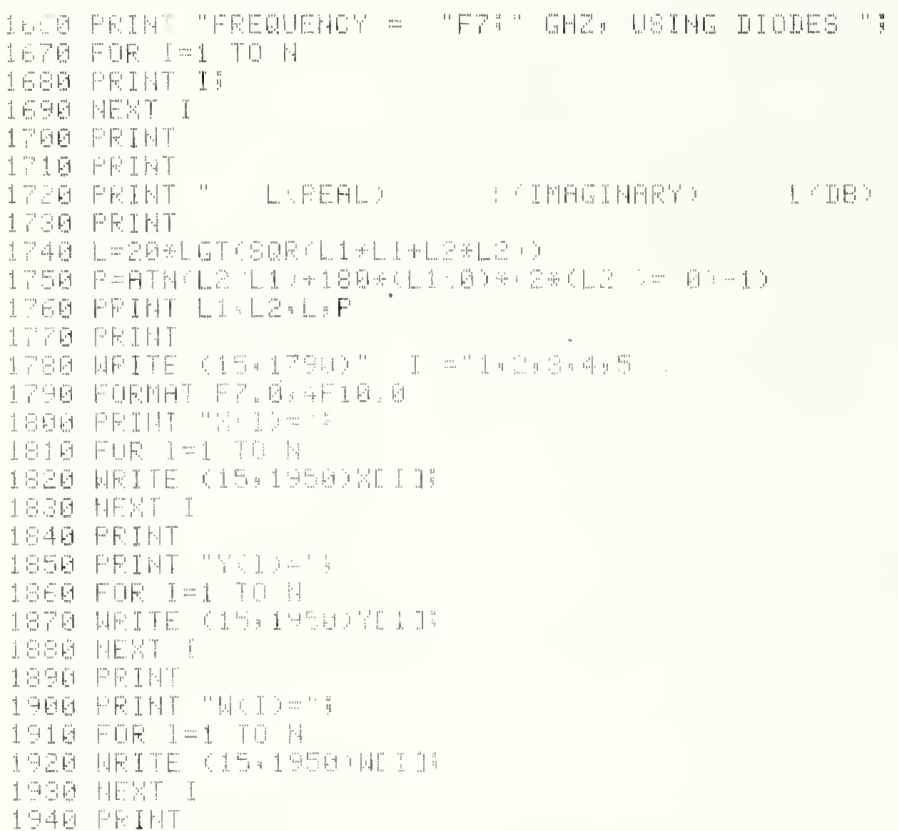

IE $\quad$ Measure $\rho_{0}$ and $C$

Print

Constants 


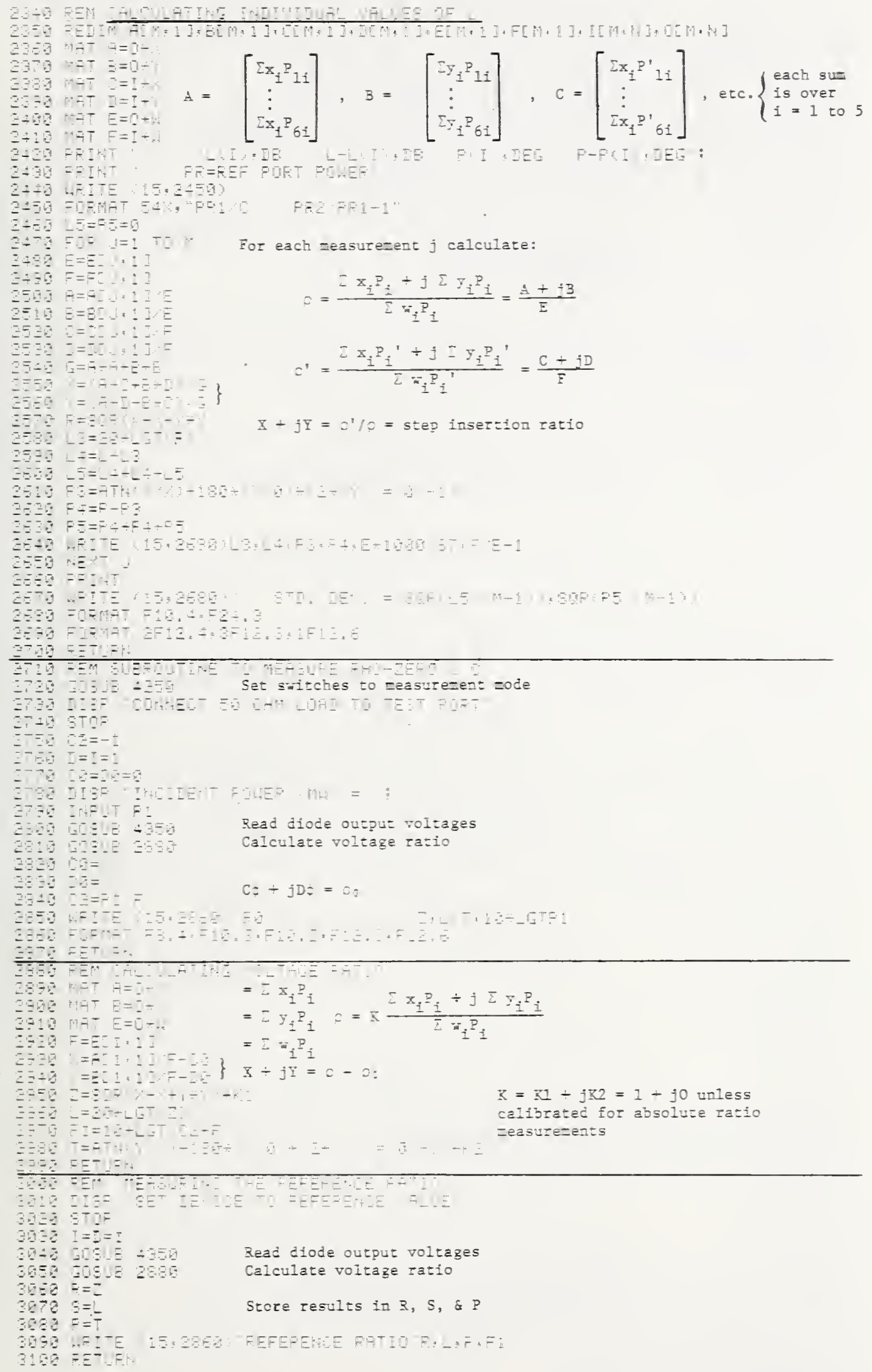




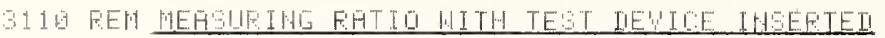

G12G IISF "INSEFT TEST ITEN OF SET IIEYICE"

3136 STOF

314 国 $I=I=1$

3156 GOSUE 4 350

3EG LOSUE 2806

Read diode output voltages

$3170.9 F^{\prime} 1=T-F^{\prime}$

Calculate voltage rat1o

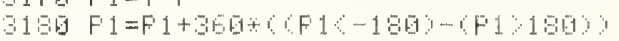

3196 GOT1 321日

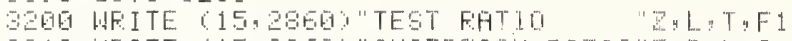

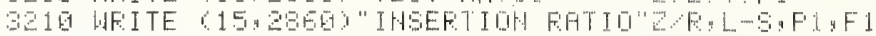

3200 FEETIIFH

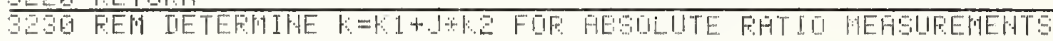

3246 IISF "AFFL'

9250 ETOF

9EG GOLE 4250 Set switches to measurement mode

$32701=\mathrm{I}=\mathrm{I}=1$

$3289+2=0$

106 Read diode output voltages

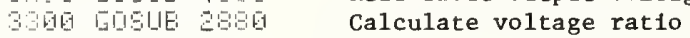

$311=12 \quad K 1+j K 2=K$

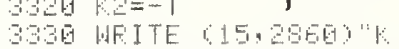

34⿴囗十 FETILA.

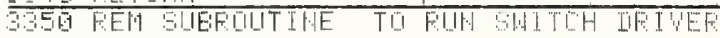

3ER HAIT 5 G

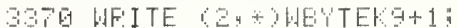

380 月IIT 5 G

33GE F'ETLLFH

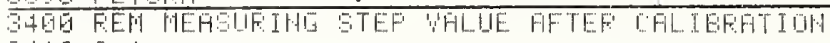

$3410 \quad I=1$

3420 GISUE 3540

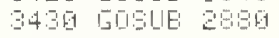

$344 \quad F=2$

$345 \mathrm{~B}=\mathrm{L}$

HF $F=T$

$3476=F$

$34 \mathrm{BG}$ FIAT $\mathrm{II}=\mathrm{B}$

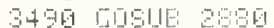

Measure diode vo1tages with step "out", step "1n" Calculate voltage ratio for step out.

956 $\mathrm{F} 1=\mathrm{T}-\mathrm{F}$

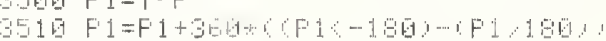

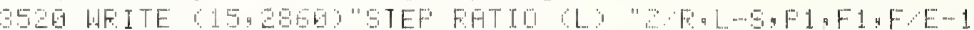

I5IG FETIIFH

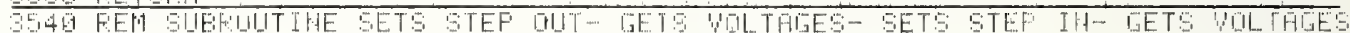

355 AFITE 1, HETEA

S5E 101

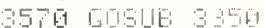

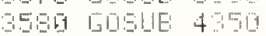

Store results in $R, S, P, E$.

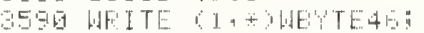

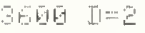

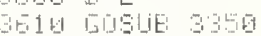

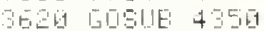

3E 3 G FETLFH

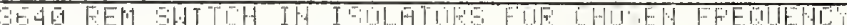

3ESG IF F T.E THEH 37.30

QEED IF FP THEH 37 BE

SETA. IF FP. 4 THEH 383

उEs $1+1=28$

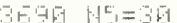

$976017=24$

$010+18=28$

37.

$3760+15=31$

$37+6+16=25$

$375017=25$

37E $+4=2$

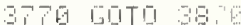

$37001+5=1$

$379+16=2$

38616 H $=25$

$3916+19=23$

15日 GT

3036 怕 $=36$

$39+1616=29$

3856 H $7=24$

0806 HE= 23

9E7G WFITE C1 $4+3$ HE TEHS:

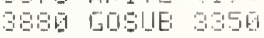

8896 WFITE C1, + HEYTEHE;

3960 GOSUE 355

Set step "out"

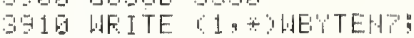

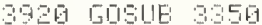

939 LFITE 1 , HAETEHE:

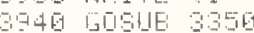

OGSE FETIJFH

For $2 \leq \mathrm{f} \leq 4$

For $8<\mathrm{f}<12$

For $0.5 \leq \mathrm{f}<2$

For $4<\mathrm{f} \leq 8$

Set isolator switches 
27 IHF.T

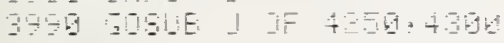

4.160

Set switches to measurement or callbration mode

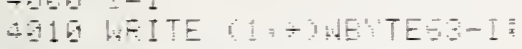

Note: Change I to monitor a diode other than 1

4 A

$4-B=5-11[-1]$

4 ITIISTH

4 G

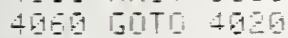

Connect output of dlode

Read DVM range code (A) and digits (B)

Multiply $B$ by proper range constant

土TF FETHEH

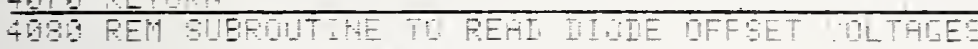

4 QSG IISF "THFH FIUEF DIFF"

4160 STOF

4110 MFT FI=ZEF

Set all offset voltage readings to zero

4120 FIYEI 1

$4136=1=1 \quad-1 H$

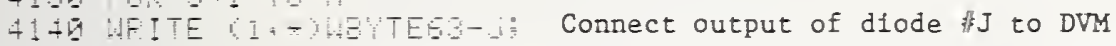

415 H H IT 5 G

410 Read diode offset voltage

$4170[1]=E$

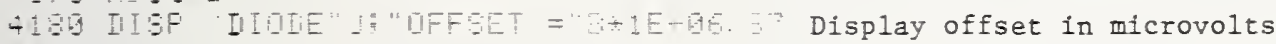

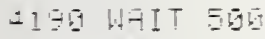

$420 \mathrm{G}$ HEYT I

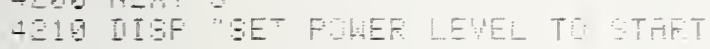

$4205 T O F$

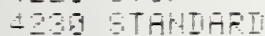

4345 FETLEH

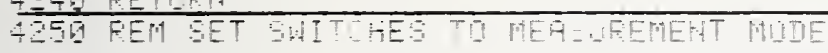

$42610 \%=3$

$42 T$ HFITE I TOHE TE

4206 LOSE $30=$

$4=9$ GETI: $F$

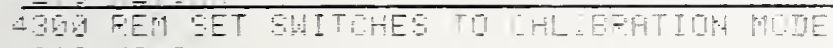

$+210+7=1$

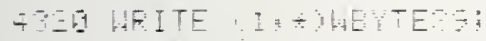

430 log 30 OE

436 FET IFH

- B FEM FEFI II

$\triangle B E$ FIF $I=:$ TO H

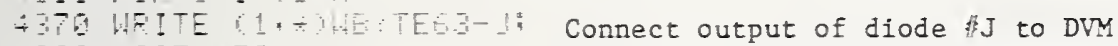

480 HEIT 150

430 IIIUE $4+4=1$

446 IF I $=2$ THEH $\div 4+3$

$4+1001=1]=0$

$442 T H E T$

40 GIT

$14+1$ II I $\div 1=$

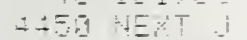

$+A-B-E^{T}=\mathrm{CH}$

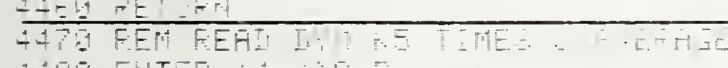

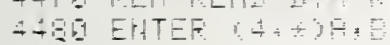

$4+36 \bar{B} 1=\mathrm{E}+M[\mathrm{FI}$

4.101 EHTEF

$\div 15 \quad E=E+15=$

15 TF HFI

If HE: E: 1 - $=-H E+4=$

Read DVM

$4=5 \quad B+=E$

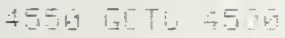

Store data in 0 matrix if $D=1$, or in I matrix if $D=0$.

$4=2 \quad 5=2$

$4=-\bar{F} F, \quad: 1 \div=$

4 GD EPTEF

4 HQT HIT

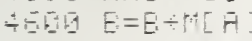

$4=1.91=-8$

$4=2$ H HEYT H4

$+E B E=1+5$

See line 4020

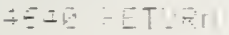

Program discards DVM readings until two consecutive readings agree to better than $1 \%$ : Program then accepts next $\mathrm{KJ}$ readings.

Read DVM K5 times, compute average, then subtract offset voltage. 


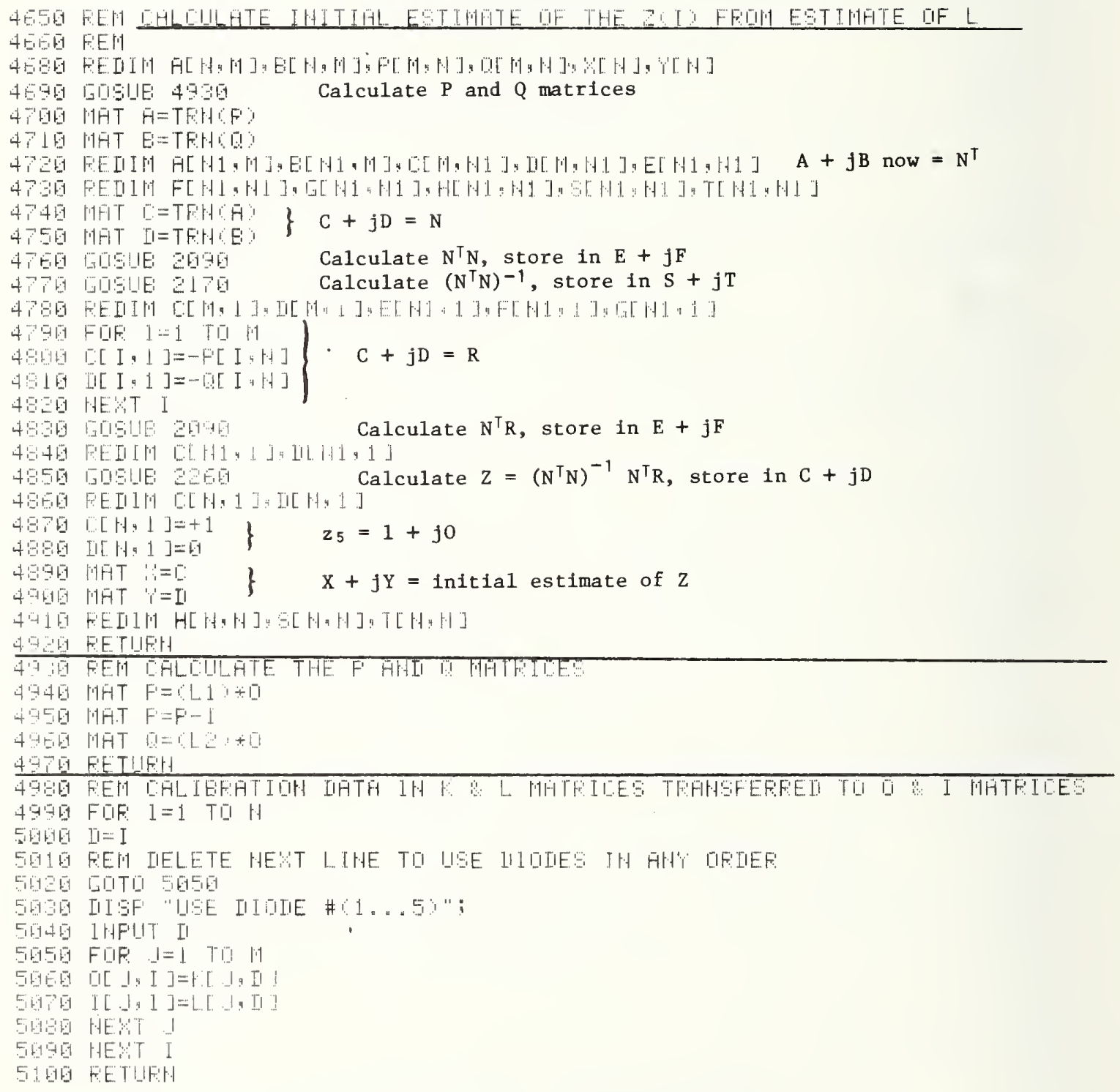


EHTEF 1 TD DHLIERATE UEOTOE WOLTIETER

EHTEF 2 TO MEASUPE FEFEFEHE PHTTO

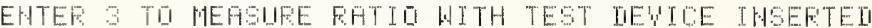

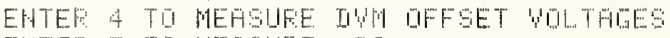

EHTEF 5 TO MEASUEE FE

EHTER E TO HOHITIF FEFEFEHEE IIOHE

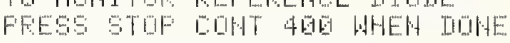

EHTEF ? TO MEASUFE 3 TEF ULLIIE L

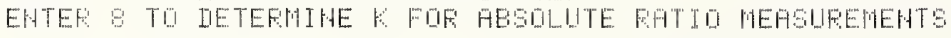

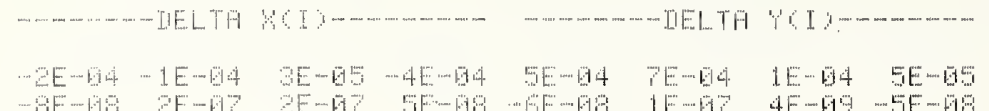

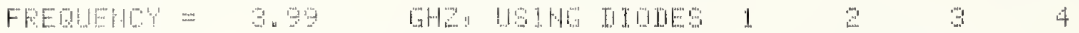

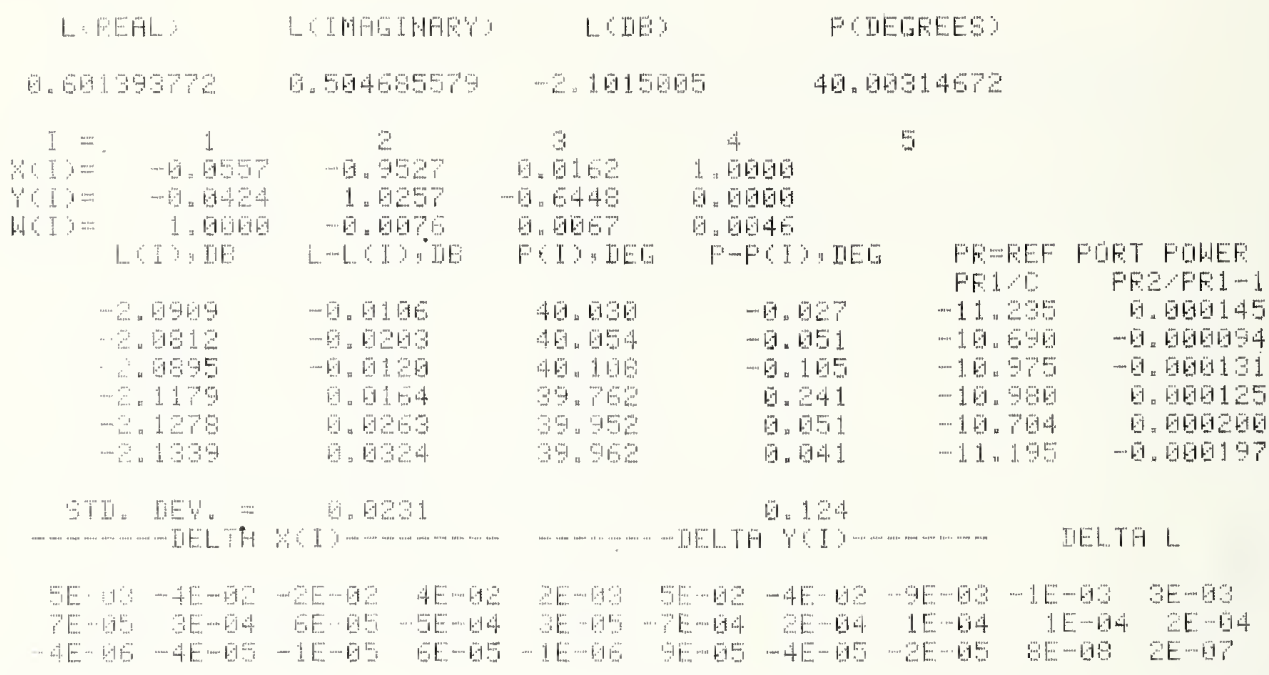

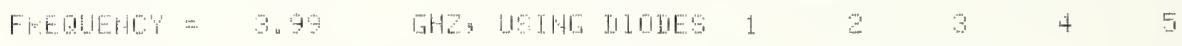
L.PEFL

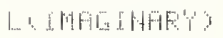
(... 40
F DELEES

4. 20265158

1. 51276445

2.110190

39.753194

$$
\begin{aligned}
& I=1
\end{aligned}
$$

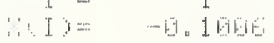

$$
\begin{aligned}
& y 1)=-1+000 \\
& \text { HCI = 1. } \\
& \text { LCI Y DE } \\
& -2 \cdot 1180 \\
& \text { 2.1157 } \\
& 119 \\
& 2.1159 \\
& \therefore 1144 \\
& \text { : } 1146
\end{aligned}
$$

\begin{tabular}{|c|c|}
\hline 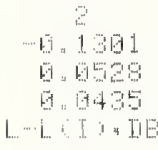 & 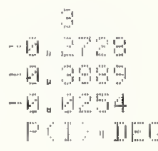 \\
\hline 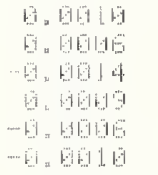 & 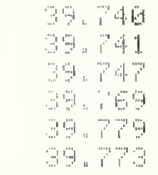 \\
\hline
\end{tabular}

\begin{tabular}{|c|c|}
\hline 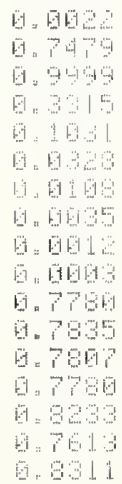 & 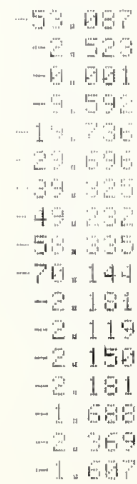 \\
\hline
\end{tabular}

GTI. IEY. =

T'Y'FE

MEHSUFEMEHT

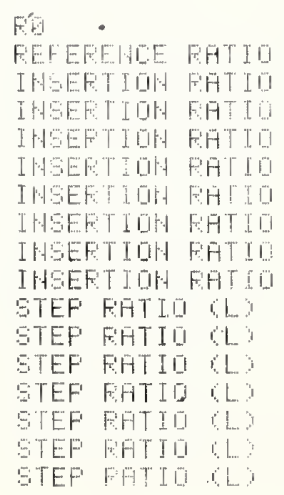

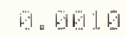

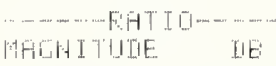

$$
\begin{aligned}
& 45 \\
& \text { a. } 514 \\
& \text { Q } 65 E \\
& \text { 1. } 6010 \\
& \text { a } \\
& \text { 1. } 147
\end{aligned}
$$

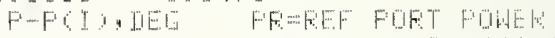

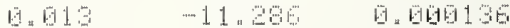

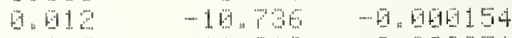
6. $017 \%-1,019$ -

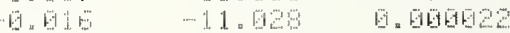

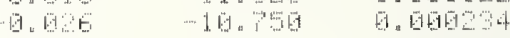
$-6.624 \quad-11.244 \quad-6,65101$

\section{日. 618}

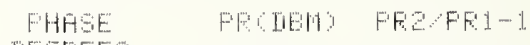
IIE TFEES

$$
\begin{aligned}
& -126.75 \\
& \begin{array}{r}
-139.22 \\
-19.64
\end{array} \\
& \begin{array}{l}
10.04 \\
-3.25
\end{array} \\
& \text { 2. } 42 \\
& -8.67 \\
& \text { 1. } 1.65 \\
& 5.34 \\
& 41.97 \\
& 16 \cdot 3 \mathrm{t} \\
& 40.25 \\
& \text { 19. } 8 \\
& 99.93 \\
& 40.29
\end{aligned}
$$
FFI FEP 1

$$
\begin{aligned}
& \text { 19.616 } \\
& \text { ‥ } 961 \\
& \text { 日. } 011 \\
& \text { - } 6.6 \\
& -1,012
\end{aligned}
$$

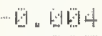

$$
\begin{aligned}
& \text { - } 4 \text {. } \\
& \text { - } 6.96 \mathrm{E} \\
& \text { - } 6.067 \\
& \text { - - . } 017 \\
& \text { - } 5.51 \\
& \text { - } 1,469 \\
& \text { - 国, 因 } \\
& \text { - } \\
& \text { - - D. D. } \\
& \text { - - 6. } 11
\end{aligned}
$$$$
\text { 9. } 161023
$$

.




\section{APPENDIX D}

\section{INTERFACE CABLE PIN CONNECTIONS}

These tables list pin connections for the interface cables indicated in figure 1 (page 2). The tables can be found at the rear of the chassis of each unit indicated. A brief description of the signal present at those pins is given to aid in understanding or troubleshooting. 
Monitor Labs

Model 1200A Scanner

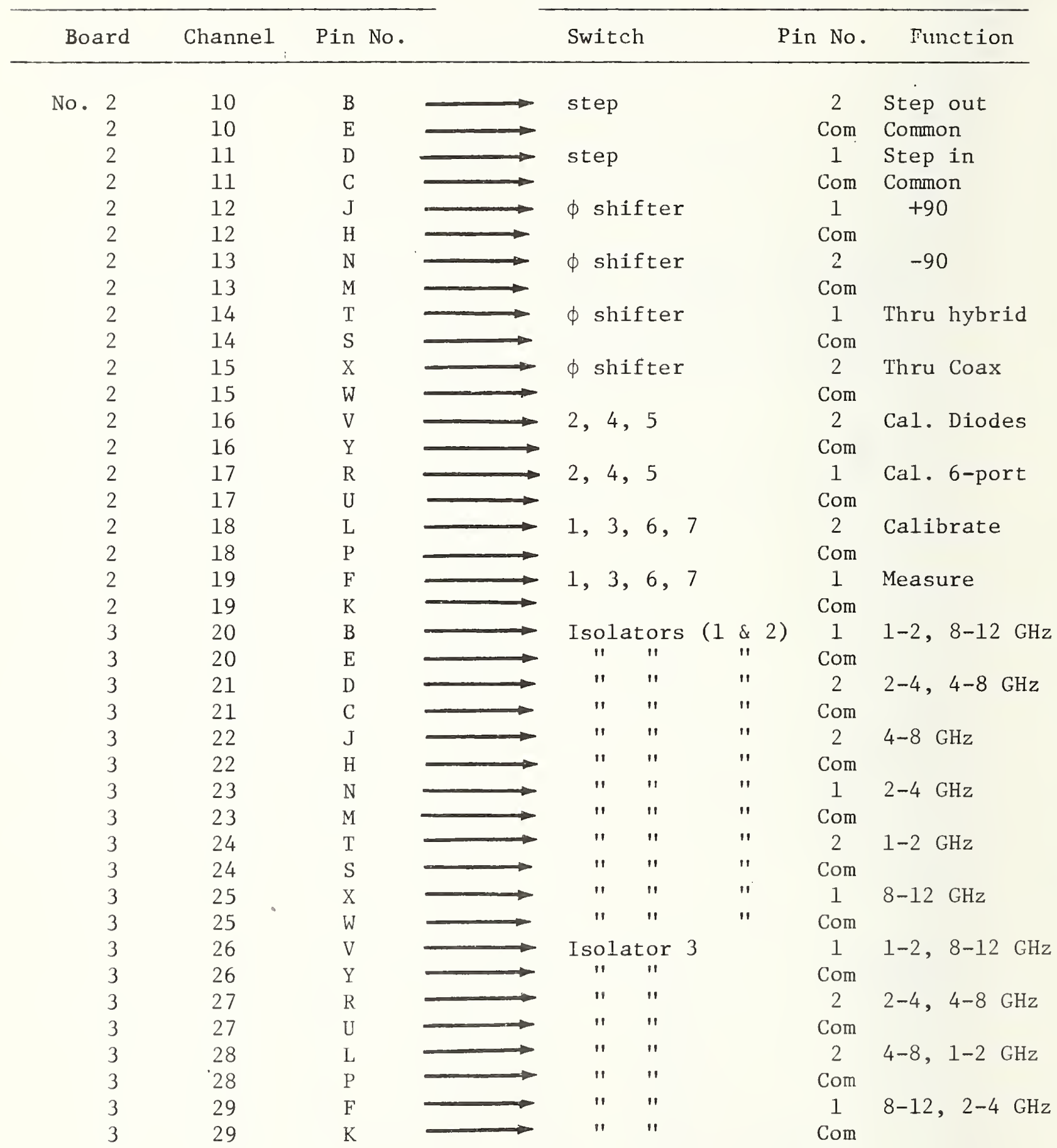


Weinschel Switch Driver

Model 120-1

Output Data Connector

Pin 2

Pin 20

Pin 3

Pin 21

Pin 4

Pin 22

Pin 5

Pin 23

Pin 6

Pin $24^{\circ}$

Pin 7

Pin 25

Pin 8

Pin 26

Pin 1

Pin 19
Io

MVV

Pin Connection on device

+ on $1 \mathrm{db}$ Step in Test Channel

- on $1 \mathrm{db}$ Stap " " "

+ on 2 dB Step " " "

- on $2 \mathrm{~dB}$ Step " " "

+ on $4 \mathrm{~dB}$ Step " "

- on 4 dB Step " " "

+ on $8 \mathrm{~dB}$ Step " " "

- on 8 dB Step " " "

+ on 5 dB Step in Reference Channel

- on 5 dB Step " " "

+ on $10 \mathrm{~dB}$ Step " " "

- on $10 \mathrm{~dB}$ Step " " "

Terminal strip (Not used)

Terminal strip (Not used)

Monitor Labs Scanner Pin 4 (J2 Boards 2 \& 3)

Monitor Labs Scanner Pin 2 (J2 Boards 2 \& 3) 
Interface connections from Data Precision Model 3500 DVM to HP computer interface cable 11203A BCD Interface

\section{Data Precision} Model 3500 Connector Pin 非
Information Direction
Hewlett Packard $11203 \mathrm{~A}$ Interface Wire \#
Comments on description

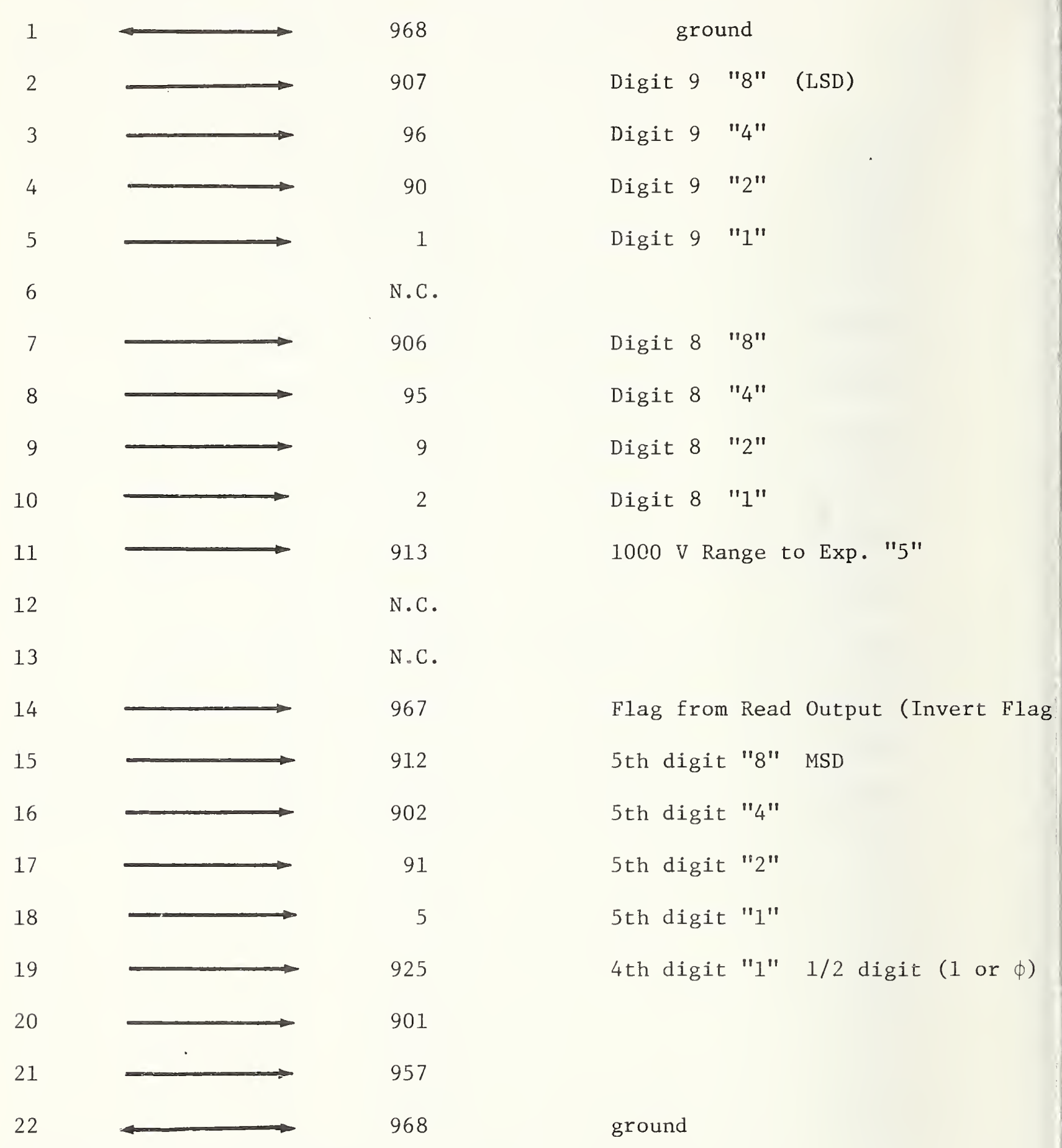


Data Precision Mode1 3500 Connector Pin 非
Information

Direction

Hewlett-Packard

11203A Interface Wire 非

Comments on description

A

B

C

D

E

F

$\mathrm{H}$

J

K

L

M

$\mathrm{N}$

$\mathrm{P}$

$\mathrm{R}$

S

$\mathrm{T}$

$\mathrm{U}$

V

W

$\mathrm{X}$

$\mathrm{Y}$

Z
968

98

908

93

7

4

92

958

N.C.

N.C.

N.C.

905

94

8

3

$\phi$

N.C.

N.C.

N.C.

6

916

968 ground

10 volt range to Function "4"

Digit 6 "8"

Digit 6 "4"

Digit 6 "2"

Digit 6 "1"

1 volt range to Function "2"

Control 1 to Enable

Digit 7 "8"

Digit 7 "4"

Digit 7 "2"

Digit 7 "1"

100 volt Range to Exp "1"

100 mv Range to Function "I"

Overload to Exp. sign

ground

Ground: 903; 908; 917;918; 923;924;926; 927; 928;

$934 ; 935 ; 936 ; 937 ; 938 ; 946 ; 947 ; 948 ; 956$. 
Monitor Labs

Model 1200

Scanner

Connector J2
To

Data Precision

Model 3500

DVM

Rear Panel Input Connectors
Pin 2

Pin 4

Pin 3

Weinschel Switch Driver

Mode1 120-1

Connector Pin No.
To

$\begin{array}{ll}\text { Pin } & 1 \\ \text { Pin } & 19\end{array}$

High

Low

Guard
Monitor Labs

Model 1200 Scanner

Pin No. on J2 (Boards 2 and 3 )

Pin 4
Pin 2


HP 11202 Connections to Monitor Labs Scanner

Mode1 1200

HP 11202 Interface

Pin Connections

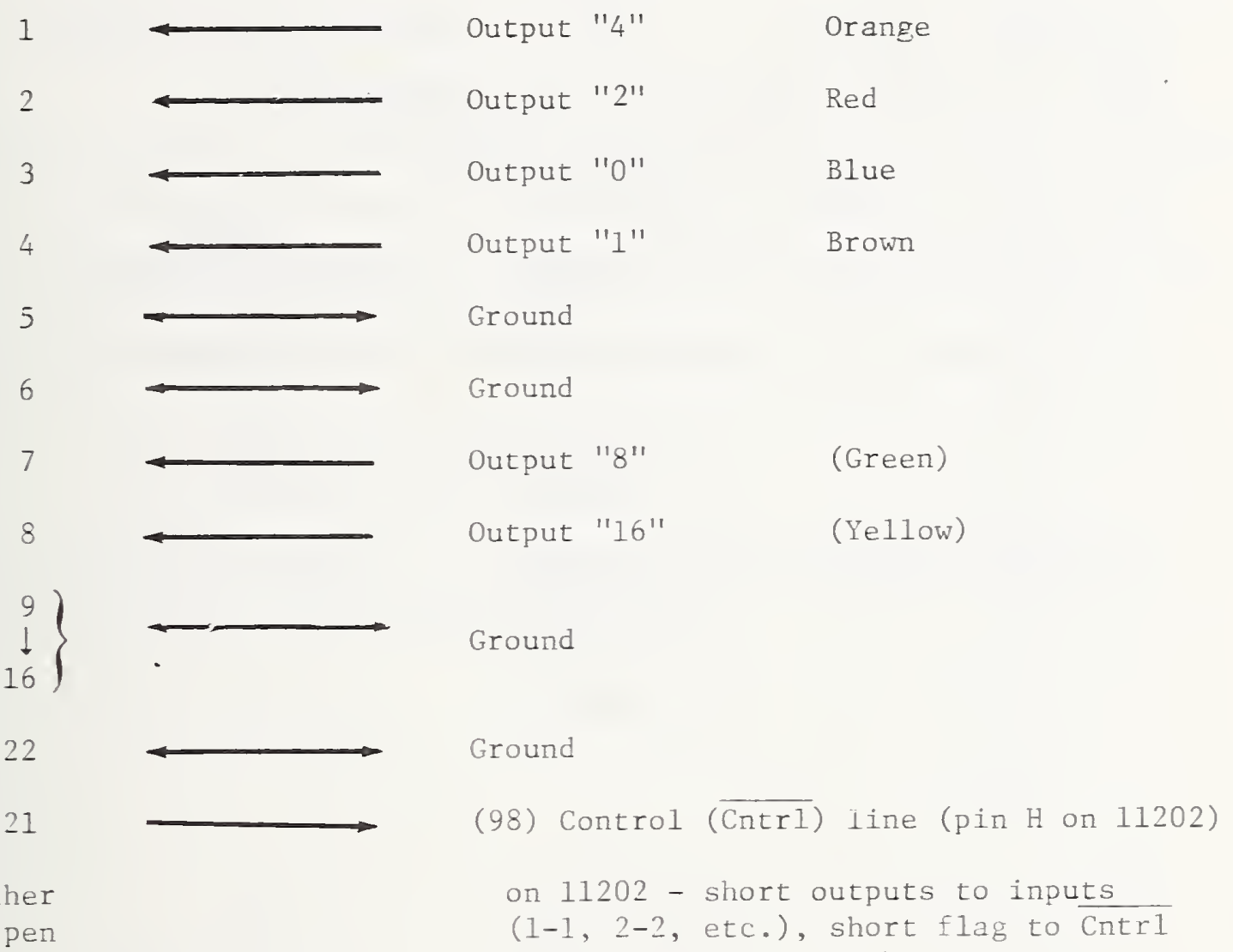

Al1 other

pins open

on 11202 - short outputs to inputs
$(1-1,2-2$, etc.), short flag to Cntr1 
HP 11202A Interface

Unit to HP 9830

Mode1 120-1

Weinschel Switch Driver
Pin 3 of UI $\phi B$

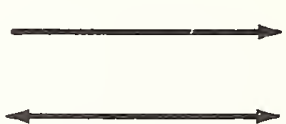

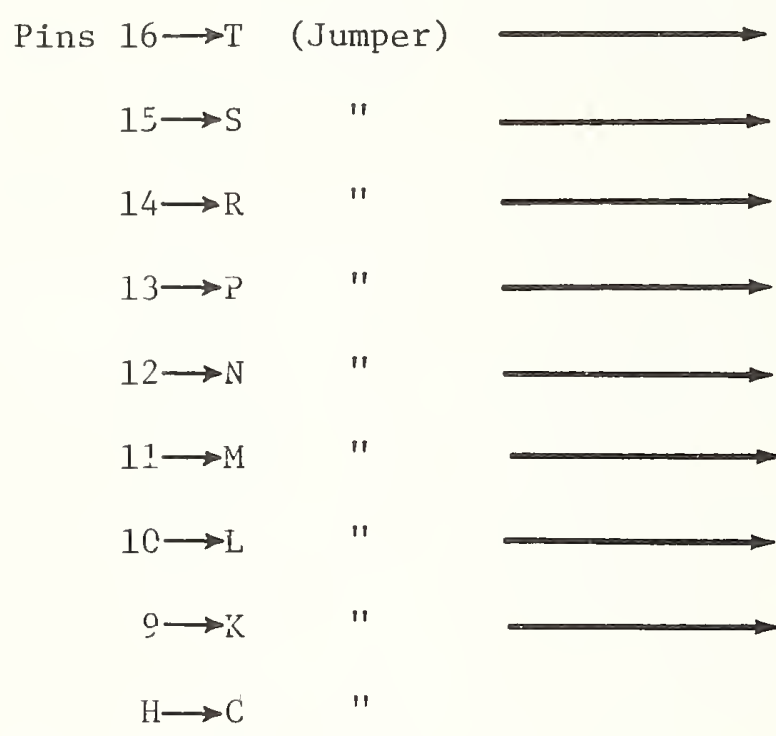

$\mathrm{U} \rightarrow \mathrm{V}$

\author{
Pin 11 (Control Pin 1) \\ 12 (Control Pin 2) \\ 13 (Control Pin 3) \\ 14 (Control Pin 4) \\ 15 (Control Pin 5) \\ 16 (Control Pin 6) \\ 17 (Control Pin 7) \\ 18 (Control Pin 8)
}

9 Strobe

27 Signal ground 


\section{APPENDIX E}

\section{DIAGNOSTIC PROGRAY LISTING WITH}

SAYPLE PRINTOUTS

This appendix contains a listing of the diagnostic program stored on file 4 of the MVV cassette tape.

Three separate tasks can be selected when using program. They are:

1. Measure step repeatability

2. Measure diode Iinearity

3. Monitor source stability.

The program was written to be an aid for setting up the system and for troubleshooting. Remarks have been added to the program listing to explain the functions of the program statements. 


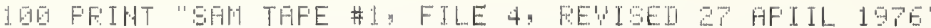

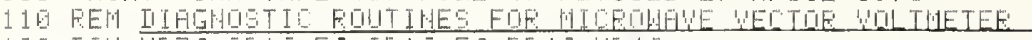

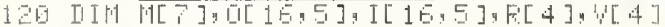

$13[\mathrm{H} H[\mathrm{E}]=-1 \mathrm{~B}$

$146[5]=-106$

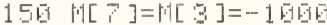

$1609=0$

179 WHT $[:=2 E F$

1 1日G WHT $F=Z E F$

19 G WHT $0=2 E F$

EGE HAT $I=Z E F$

210 IISF "FFEO IH FHz"

2IIFIIT FT

23G FFIHT "FFEG = "FF" LHZ"

246 FFIHT

25. TISDE 1516

Switch in appropriate isolators

ZEG FFIHT "EHTEF 1 TO HEAGUFE STEF REFEATHEILIT'"'

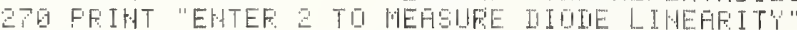

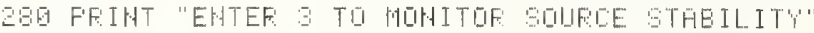

29 PFIHT

S四 IISF "THEN"

I1日 IHEIIT I

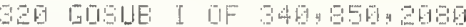

33日 GOTO 3Ë

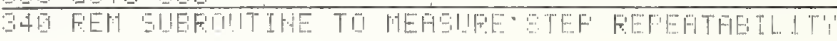

35 5010

SEG IISF "TIIFH DFF FIUAER":

37日 GTOF

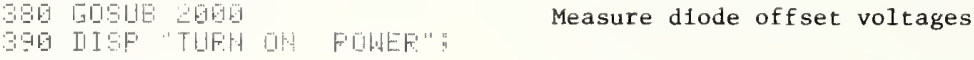

4 G日 GTOF

4 G

$4260010 \quad 576$

Choose which diode to monitor

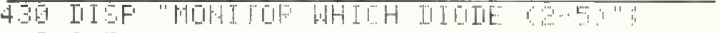

44 IFHEUT II

45 F'IFIT

4E. F'F IHAT

4 FE FEIHT

$486.1=1-1$

$49619=6$

5010

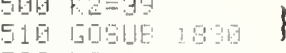

$526-2=4$

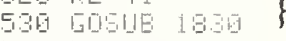

$54612=4$

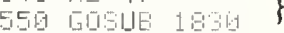

Set attenuation in measurement channel to zero

FET FEF

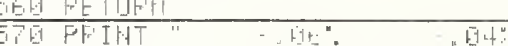

5 GE FI I T THE

FET FIHT " I. +

EDE HEITE 115919

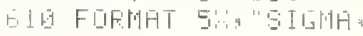

E-1 $1=1$

$63+1=5$

E40 DOSUE 3141

$E$ E $F 10=\bar{H}$

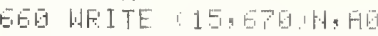

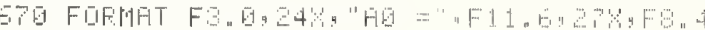

ESE TESUE 1:TE

EGG HFITE: $15,7019.19$

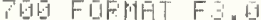

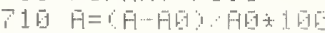

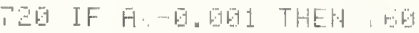

7 IE IF $\bar{A}$, GEI THEH PEB

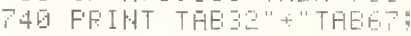

750

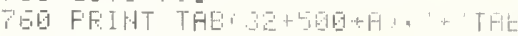

77 G⿴囗十丁口卄

7 GE FEIHT THE "THE

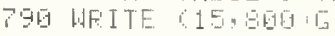

BEE FDFWAT FT'S

B16 IF AESCA, 日.

$82 G 1=k 1+1$

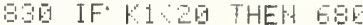

Set switches to calibration mode

Set switches to calibrate diodes

840 FETIJFH

Measure step ratio $\mathrm{N}$ times, compute average and std. dev. $\mathrm{AO}=$ initial average

Measure step ratio $\mathrm{N}$ times again

Compute \% deviation from inftial average

Plot deviations

If deviation $>.05 \%$, compute new initial average

Repeat measurement 20 times 


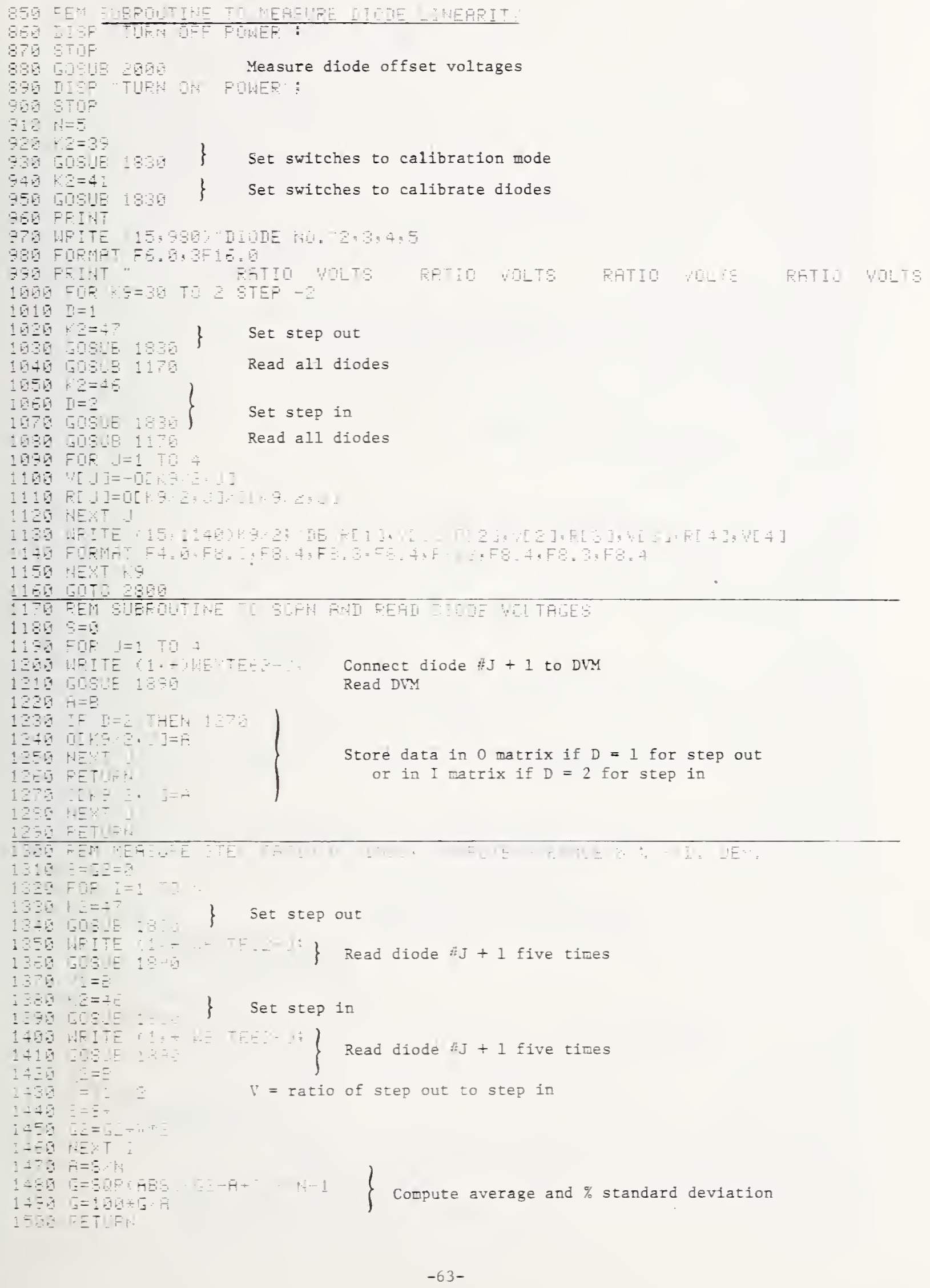




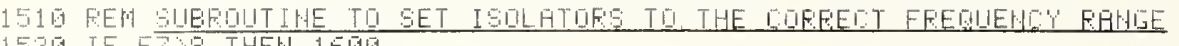

15. IF FP. THEH 1 G

15 IF FP THEH 1ESG

154 IF FP A THEH 1 T 10

$155.15=29$

1560 - $15=36$

1570 情 $=24$

$1596+18=20$

1590 1070 1740

$1 F_{1}$ 国 $+5=3$

1810 HE

$1 E 26$ H $7=25$

$1596+19=23$

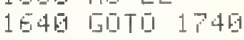

1650 - $15=3$

$16 E$ HE

1670 H $17=25$

$1636+19=23$

1690 10T0 1740

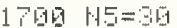

1710 HE $=29$

$1726 H^{\circ}=24$

1730 相 $=2$

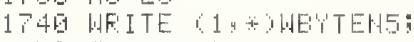

175 GISIDE 1850

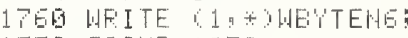

1779 GOSUE 1850

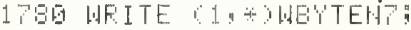

1799 LOSLE 1850

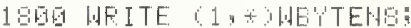

1910 LOLUE 1856

192 FETUFH

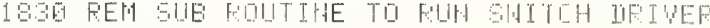

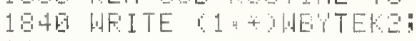

195 W H IT S

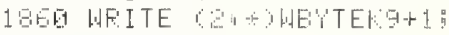

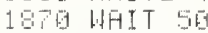

1BEA FETHEH

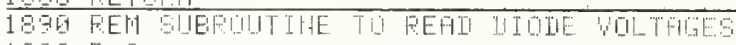

196010

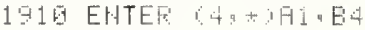

$19 \mathrm{GHF}-1$ TI 5

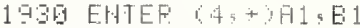

194 月 M I I T 5 G

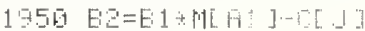

Subtract offset from each DVM reading

$19 \mathrm{~B} \quad \mathrm{E}=\mathrm{E}+\mathrm{EB}$

$197 \mathrm{OHET}$

$1950 \mathrm{~B}=\mathrm{E}$

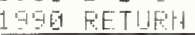

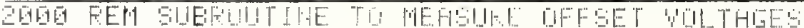

2010 WAT $D=2 \mathrm{EF}$

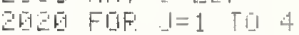

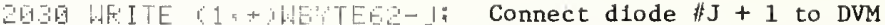

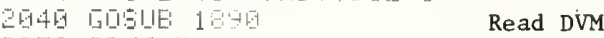

$2150[1]=E$

2EE HEYT

2GTG FETUEF.

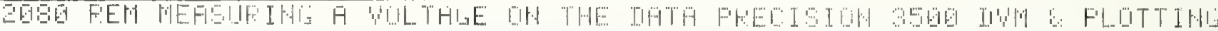

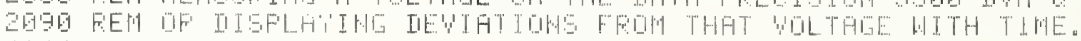

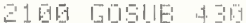

Monitor which diode?

11 WFITE 1 + WEYTEE-1: Connect diode \#J +1 to DVM

212G FIF $I=1$ TDE

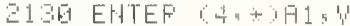

214 H HEXT I

Discard six DVM readings

2144 IHFIIT 5

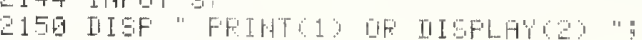

2160 IHFIIT

2170 IF $Y=2$ THEH $25: E$

2175 GITO GP DF 21969193.2197

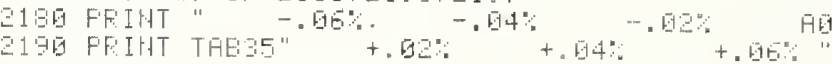

2192 1.0T0 2016

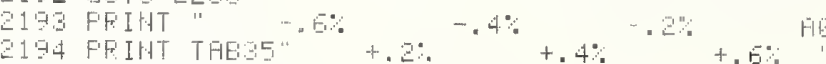

$2196 \quad 10010200$

2197 FRIAT

2198 FRIHT THES

2Q10 F'RIHT "H

2210 HFITE 15.220

2220 FDFHAT 5, "SILHA,

$225 \quad 57=19+5-1$

20 的=1国

S7 is now a scale factor \{

$S 7=1$ for $\pm 0.05 \%$ range

$S 7=10$ for $\pm 0.5 \%$ range

$S 7=100$ for $\pm 5.0 \%$ range

Headings for

different ranges 


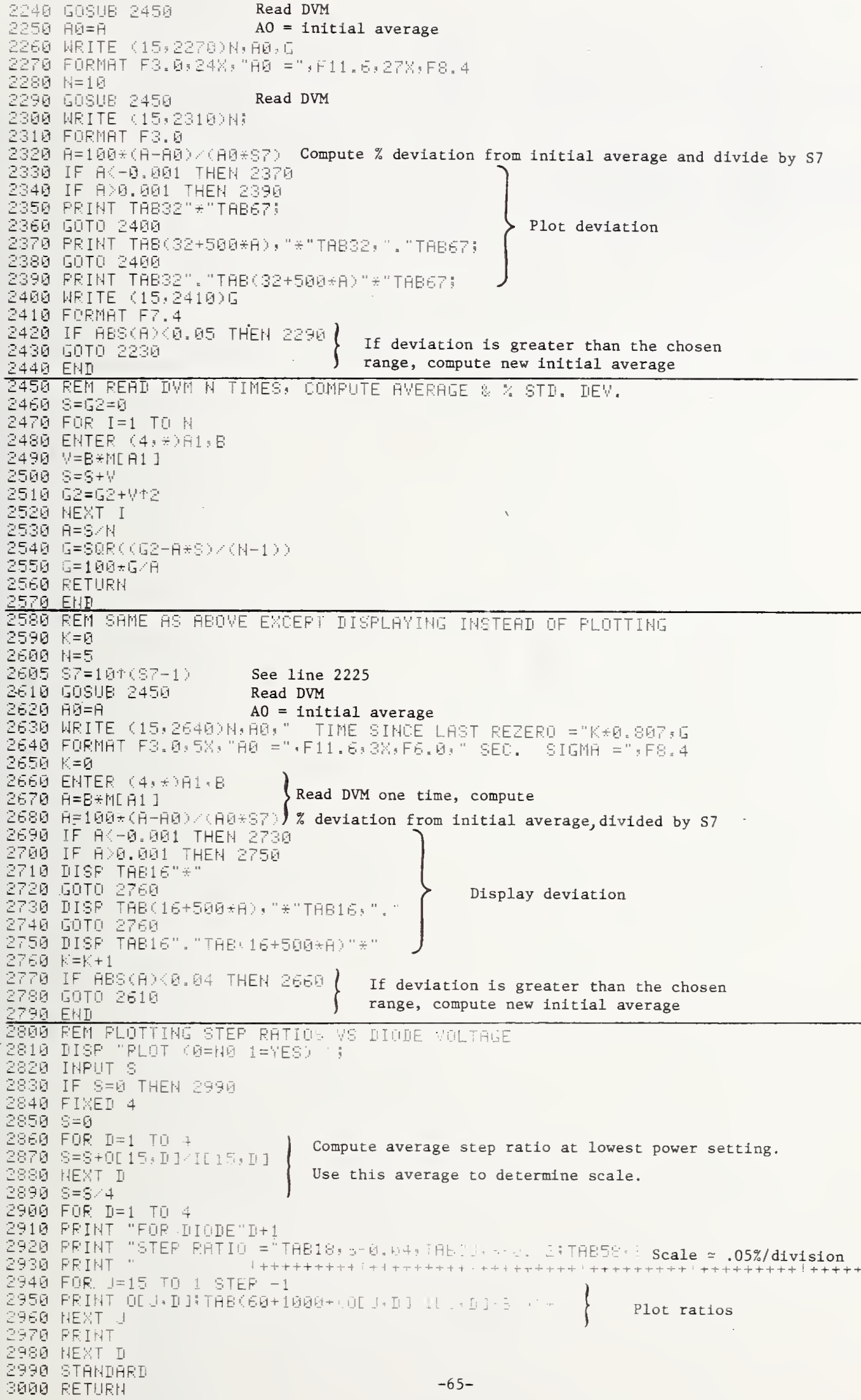




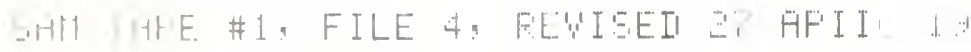

FFED - 5. 5 .

EHTEF 1 IL MEH IIFE GTEF FEFEATHEILIT'Y

EHTEF - TI MEHIIAE IIIIIE LIHEAFITY

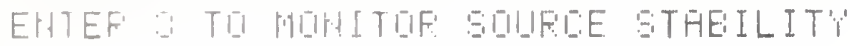

Sauple Printout

Task \#1, Step Repeatabilitv

II IIE HII I I

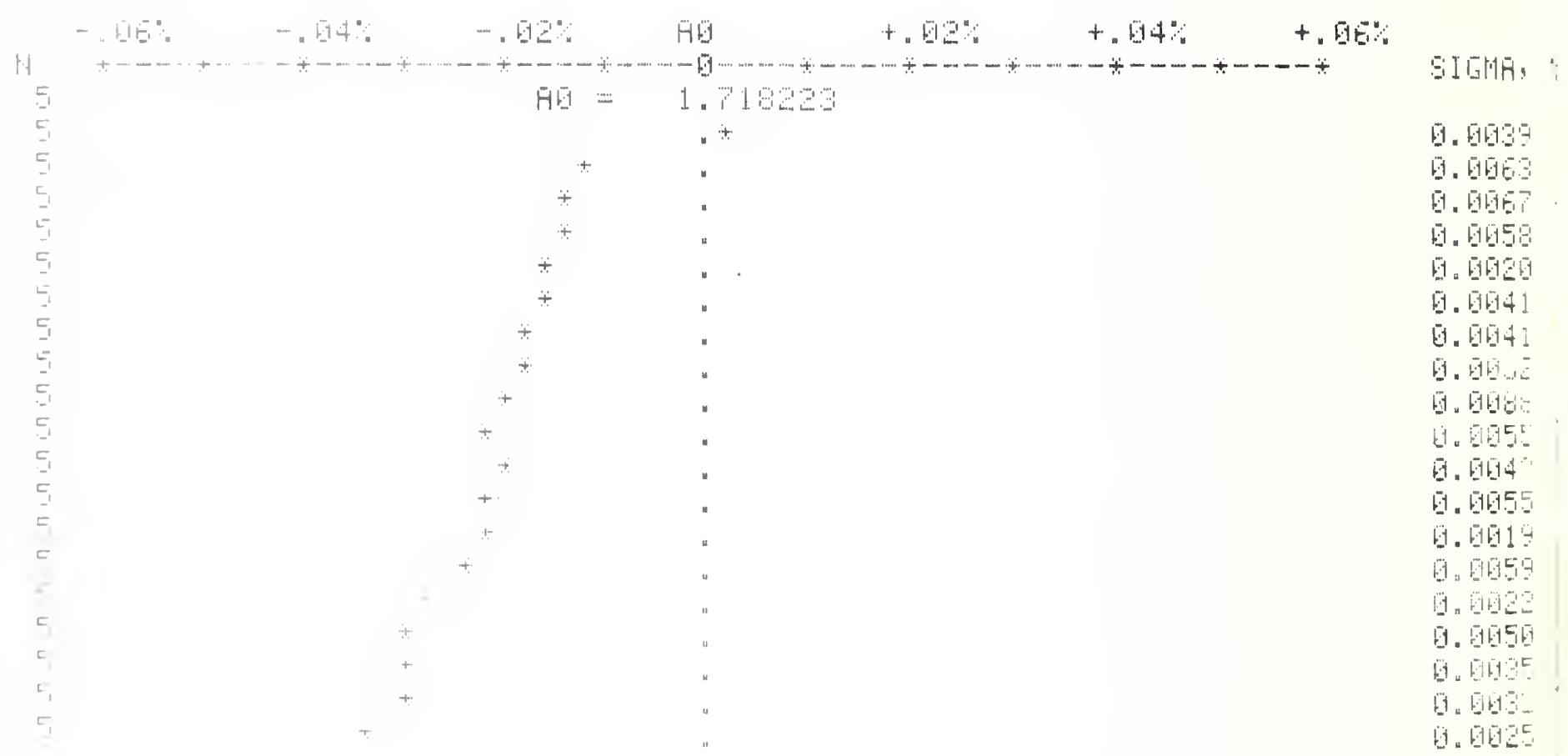


Sample Printout

Task 2, Diode Linearity

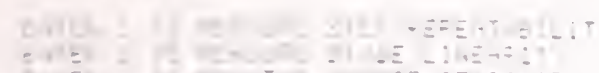

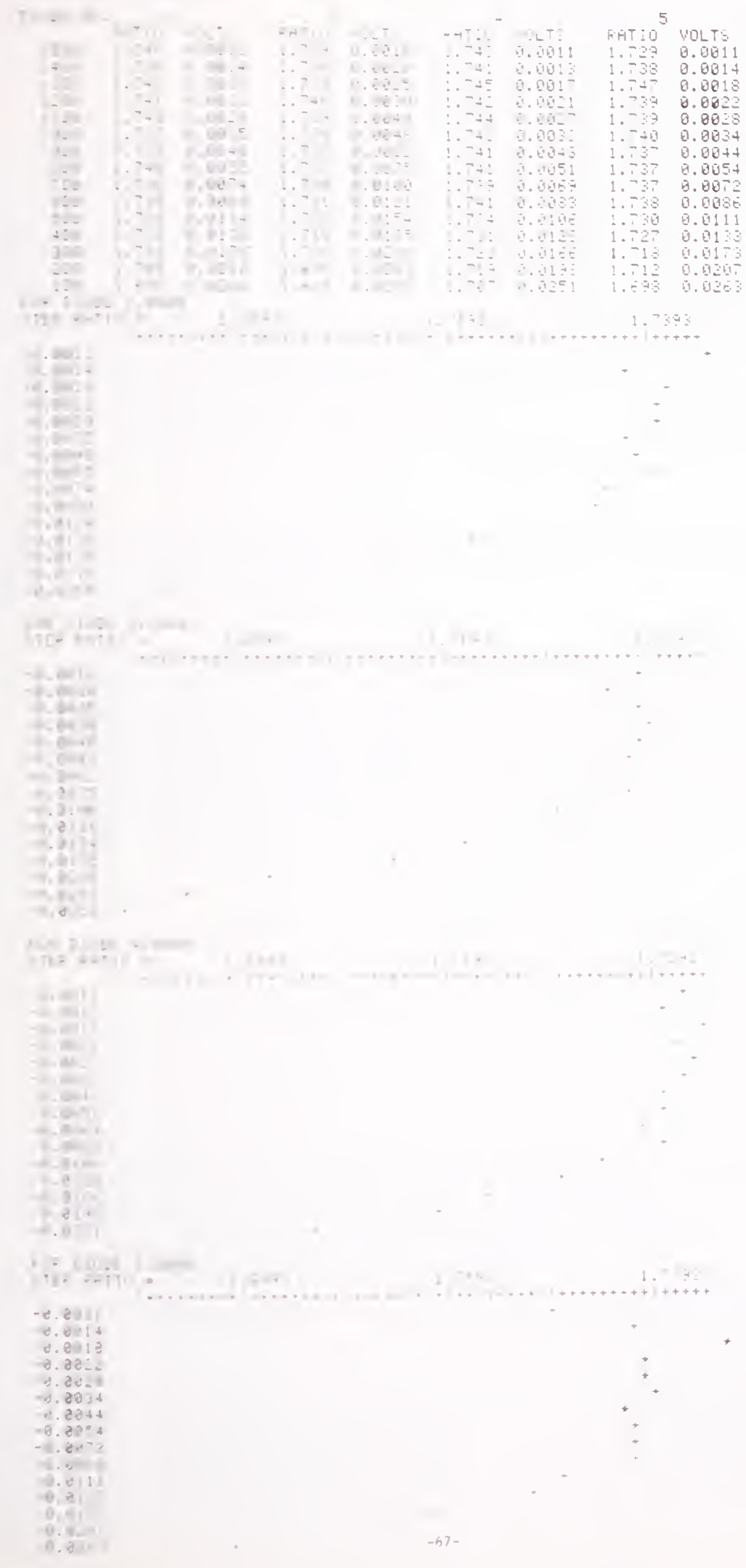




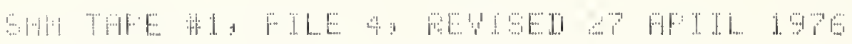

$F$ Fil $\cdots$ O

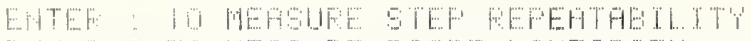

Sample Printout

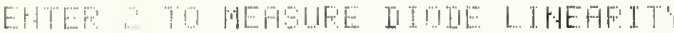

Task 3, Source Stability

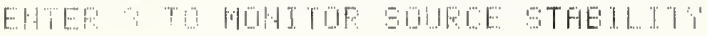

IIIUE HOW

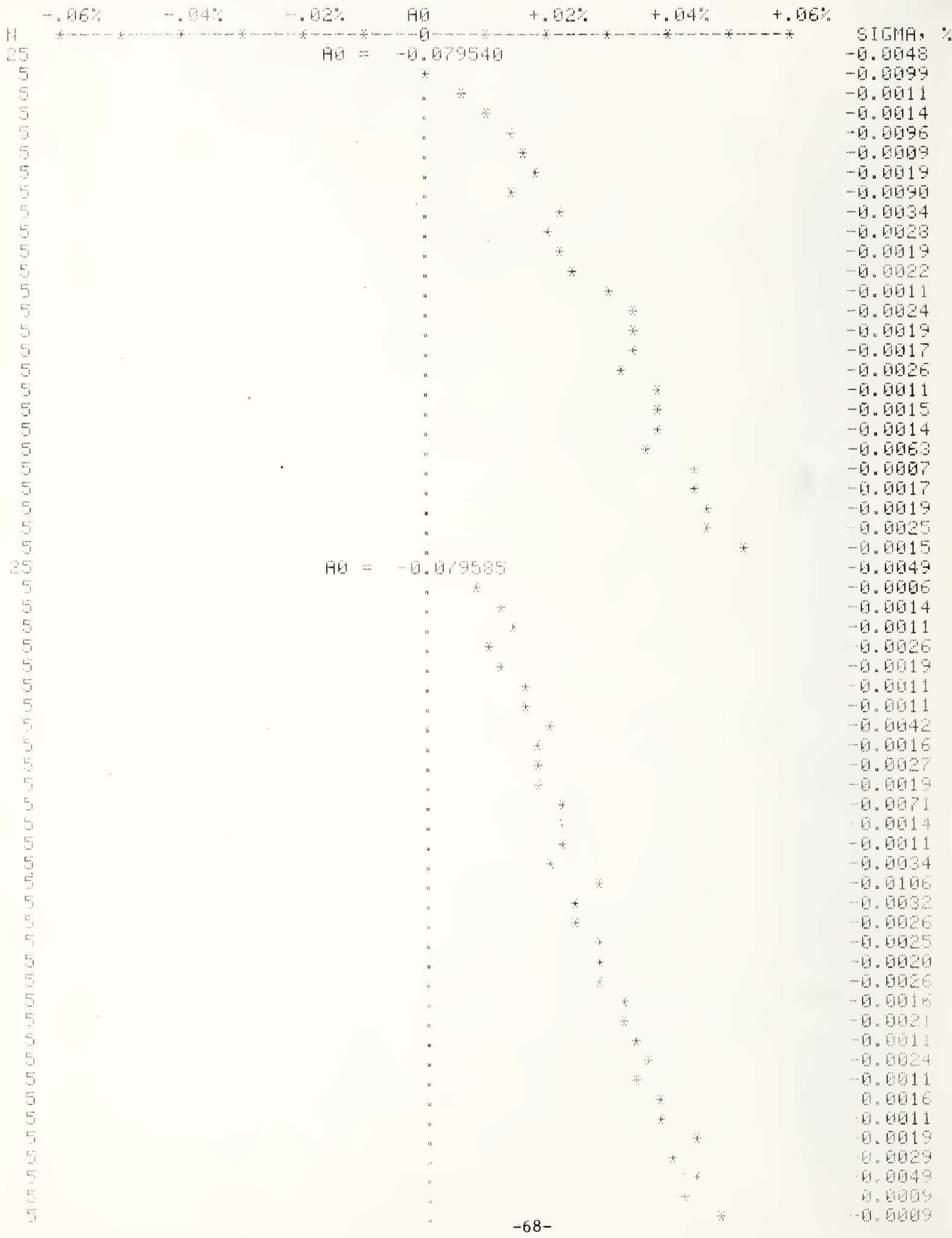


NBS.114A (REV. 7.73)

\begin{tabular}{|c|c|c|}
\hline $\begin{array}{l}\text { 1. PUBLICATION OR REPORT NO. } \\
\text { NBSIR } 76-844\end{array}$ & $\begin{array}{l}\text { 2. Gov't Accession } \\
\text { No. }\end{array}$ & 3. Recipient's Accession No. \\
\hline \multirow{2}{*}{\multicolumn{2}{|c|}{$\begin{array}{l}\text { 4. TITLE AND SUBTITLE } \\
\qquad \text { A MICROWAVE VECTOR VOLTMETER SYSTEM }\end{array}$}} & $\begin{array}{l}\text { 5. Publication Date } \\
\text { August } 1976\end{array}$ \\
\hline & & $\begin{array}{l}\text { 6. Performing Organization Code } \\
276.03\end{array}$ \\
\hline \multicolumn{2}{|l|}{ 7. AUTHersth C. Roe and Cletus A. Hoer } & 8. Performing Organ. Report No. \\
\hline \multirow{2}{*}{\multicolumn{2}{|c|}{$\begin{array}{l}\text { 9. PERFORMING ORGANIZATION NAME AND ADDRESS } \\
\text { NATIONAL BUREAU OF STANDARDS } \\
\text { DEPARTMENT OF COMMERCE } \\
\text { WASHINGTON, D.C. } 20234\end{array}$}} & $\begin{array}{l}\text { 10. Project/Task/Work Unit No. } \\
2763433\end{array}$ \\
\hline & & 11. Contract/Grant No. \\
\hline \multirow{2}{*}{\multicolumn{2}{|c|}{$\begin{array}{l}\text { 12. Sponsoring Organization Name and Complete Address (Street, City, State, ZIP) } \\
\text { Department of the Air Force } \\
\text { USAF School of Aerospace Medicine (USAFSAM) } \\
\text { Brooks Air Force Base, Texas } 78235\end{array}$}} & $\begin{array}{l}\text { 13. Type of Report \& Period } \\
\text { Covered } \\
\text { Final }\end{array}$ \\
\hline & & 14. Sponsoring Agency Code \\
\hline
\end{tabular}

15. SUPPLEMENTARY NOTES

16. ABSTRACT (A 200-word or less factual summary of most significant information. If document includes a significant bibliography or literature survey, mention it here.)

This report presents a system description and operating procedure for a vector voltmeter system which covers the frequency range .5 to $12 \mathrm{GHz}$. The design is based upon a seven-port junction where phase and amplitude information is obtained using only power detectors. The system is computer controlled and self-calibrating for ratio measurements.

17. KEY WORDS (six to twelve entries; alphabetical order; capitalize only the first letter of the first key word unless a proper name; separated by semicolons)

Amplitude; computer controlled; diode detectors;

microwave measurements; phase angle; self-calibration;

seven-port junction; vector voltmeter.

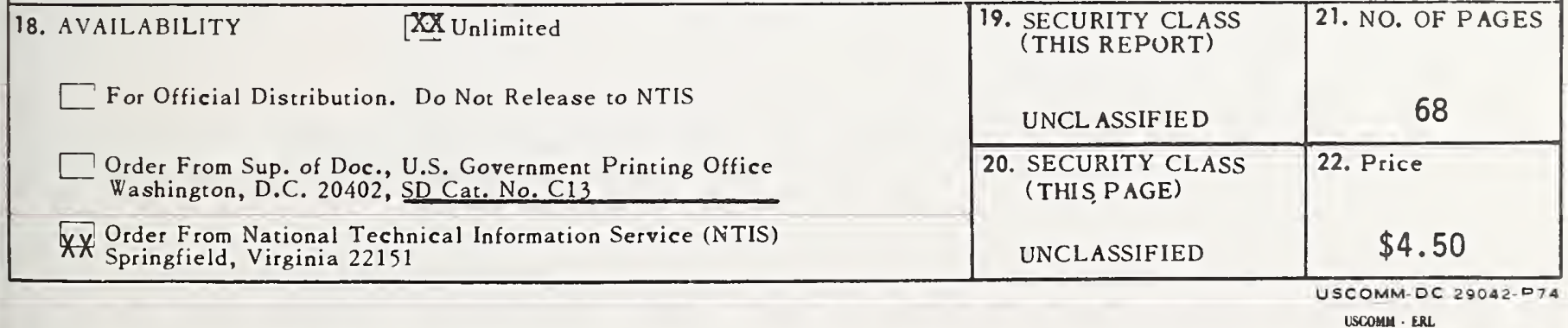


